\title{
High Energy Gas Fracturing Test
}

Final Report for the Period April 10, 2000 - August 31, 2000

Date Published: February 27, 2001

R. Schulte

\section{PREPARED FOR THE UNITED STATES DEPARTMENT OF ENERGY FOSSIL ENERGY/ROCKY MOUNTAIN OILFIELD TESTING CENTER}

Work Performed Under Rocky Mountain Oilfield Testing Center (RMOTC) CRADA No. 2000-004

Distribution A - Approved for public release; further dissemination unlimited (Unclassified Unlimited) 


\section{Disclaimer}

This report was prepared as an account of work sponsored by an agency of the United States Government. Neither the United States Government nor any agency thereof, nor any of their employees, nor any of their contractors, subcontractors or their employees, makes any warranty, express or implied, or assumes any legal liability or responsibility for the accuracy, completeness, or any third party's use or the results of such use of any information, apparatus, product, or process disclosed, or represents that its use would not infringe privately owned rights. Reference herein to any specific commercial product, process, or service by trade name, trademark, manufacturer, or otherwise, does not necessarily constitute or imply its endorsement, recommendation, or favoring by the United States Government or any agency thereof or its contractors or subcontractors. The views and opinions of authors expressed herein do not necessarily state or reflect those of the United States Government or any agency thereof. 


\section{TABLE OF CONTENTS}

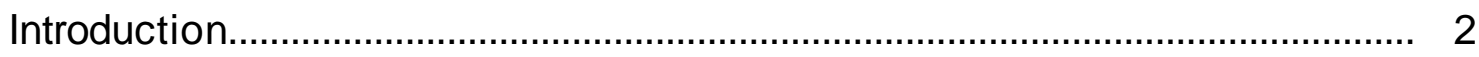

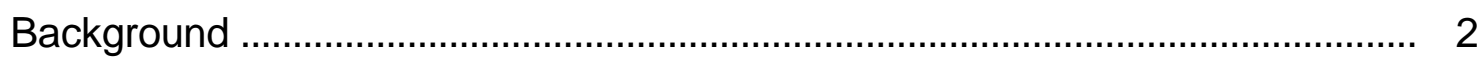

Well Selection Parameters ............................................................................. 3

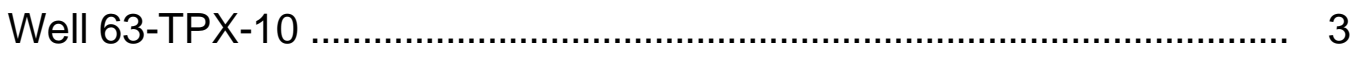

Testing Procedure ……........................................................................... 4

Modified Well Selection ...................................................................... 6

Production Baseline ……………………………………………….... 7

Testing History .................................................................................. 7

Post Stimulation Production Analysis .................................................. 8

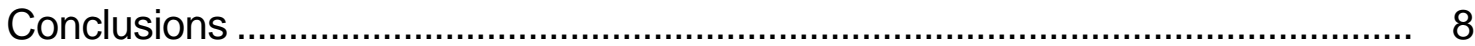

Figure 1 (Location of NPR No. 3) ………………………………………..... 2

Table 1 (NPR-3 Historical Results from HEGF) …………………………....... 3

Table 2 (Formation Characteristics of Tensleep) ……........................................... 4

Table 3 (Formation Characteristics of Second Wall Creek) …………...................... 7

Appendix A (Field Notes) ......................................................................... 10

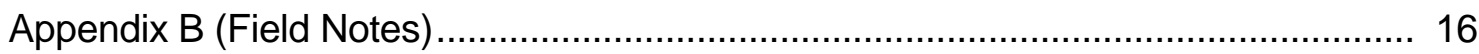

Figure 1 (Well 63-TPX-10 (Production History) ………......................................... 20

Figure 2 (Well 63-TPX-10 (Production Comparison Flow Test) ................................. 20

Figure 3 (Well 63-TPX-10 (Production Comparison Pump Test) ............................... 21

Figure 4 (Well 61-A-3 (Production History) .............................................................. 21

Figure 5 (Well 61-A-3 (Baseline Production Prior to Stimulation) ............................... 22

Figure 6 (Well 61-A-3 (Production Rate) ………................................................... 22

Figure 7 (Well 61-A-3 (Test Treater Results) ……………................................. 23

Figure 8 (Well 61-A-3 (Injection Rate and Pressure) ................................................ 23

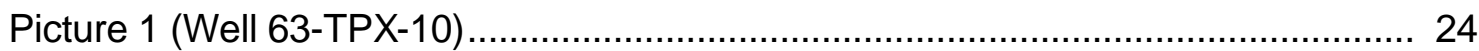

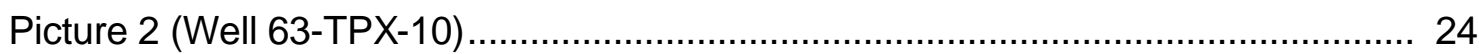

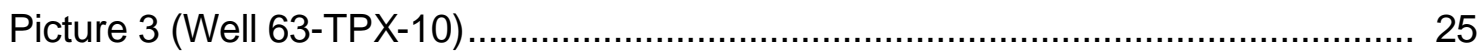

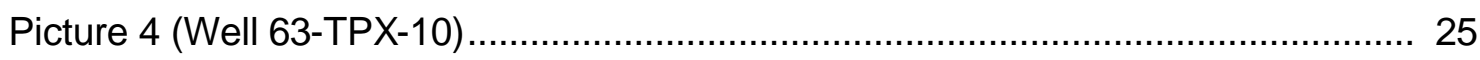

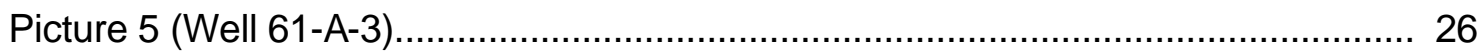

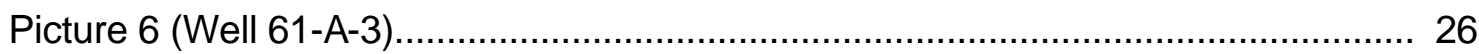

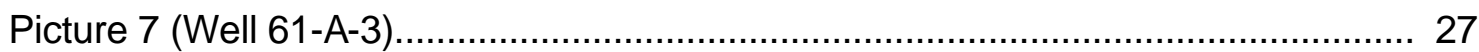

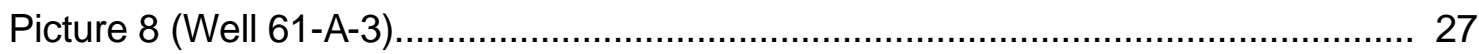

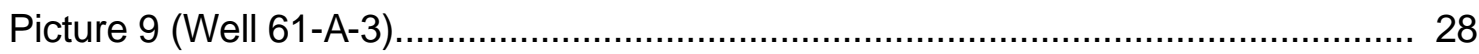

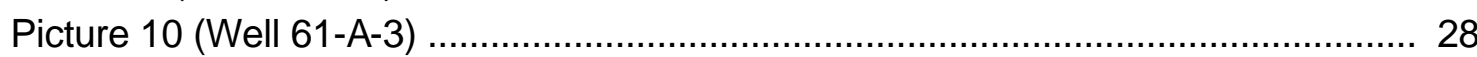

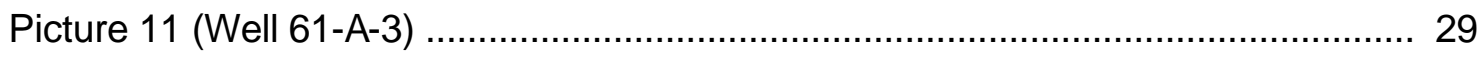




\section{Introduction}

The Rocky Mountain Oilfield Testing Center (RMOTC) has recently completed two tests of a high-energy gas fracturing system being developed by Western Technologies of Crossville, Tennessee. The tests involved the use of two active wells located at the Naval Petroleum Reserve No. 3 (NPR-3), thirty-five miles north of Casper, Wyoming (See Figure 1). During the testing process the delivery and operational system was enhanced by RMOTC, Western Technologies, and commercial wireline subcontractors.

\section{Background}

High-Energy Gas Fracturing (HEGF) involves the rapid introduction of a high pressure pulse to the formation face to create a series of limited radial like fractures. The technology of HEGF and Extreme Overbalance (EO) has been recently discussed in a four part series in the Oil and Gas Journal (See Ref.1).

An early attempt (1985) was made at NPR-3, during the pilot testing of a light oil steam drive project. At that time, HGEF was used to limit communication between steam injectors and producers

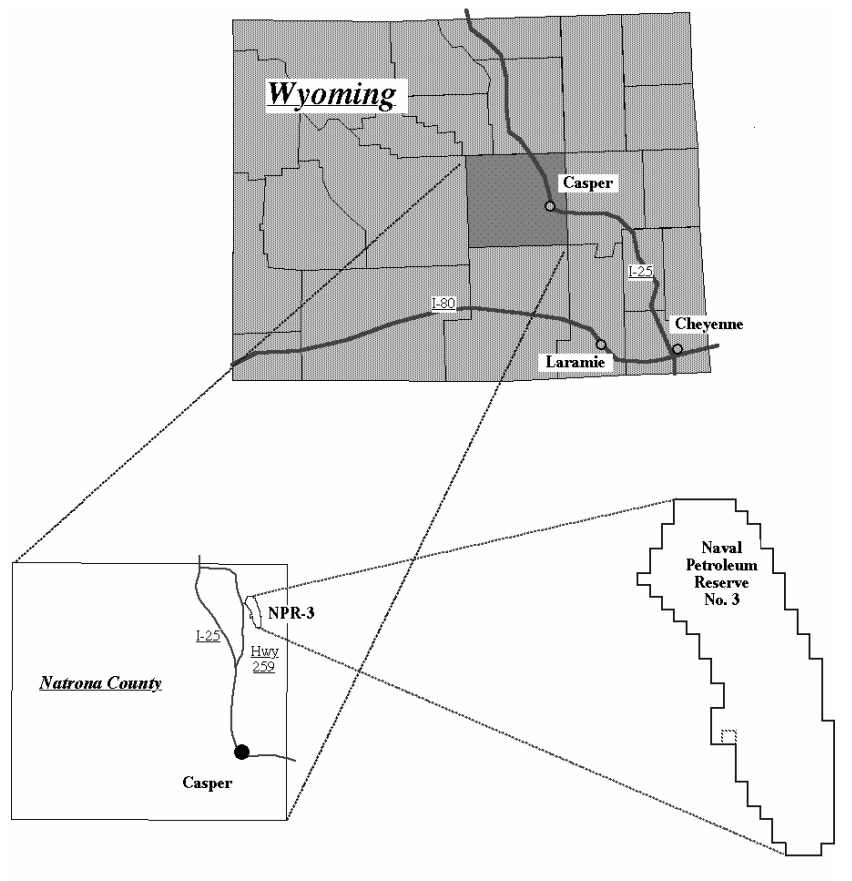
in a known fractured reservoir. Producing wells along the anticipated directionality trends were treated with the HGEF technique while wells off the directionality trend were conventionaly fracture stimulated.

NPR-3 Vicinity Map

Figure 1 Location of NPR No. 3

Table 1 summarizes the results for the wells treated in the shallow $(<500 \mathrm{ft})$ Shannon formation. Two of the five wells treated indicated greater than a three (3) BOPD response. Two of the five wells showed little response while another had a negative response of one barrel per day ( -1 BOPD). As a group, production increased $69 \%$ for oil and $185 \%$ for total fluid; however, the total increase for the five wells was only 5.6 BOPD. Recent articles in the OGJ show similar mixed results with HEGF (Ref. 1).

After reviewing the above performance and recent industry data, it was concluded that the well selection process would be critical in demonstrating the performance of any high-energy gas fracturing technique. 


\begin{tabular}{|c|c|c|c|c|c|c|c|c|c|}
\hline \multirow[t]{2}{*}{ Well } & \multicolumn{3}{|c|}{$\begin{array}{c}\text { Production Before } \\
\text { Total }\end{array}$} & \multicolumn{3}{|c|}{ Production After } & \multicolumn{3}{|c|}{ Production Change } \\
\hline & BOPD & BWPD & BFPD & BOPD & BWPD & BFPD & BOPD & BWPD & BFPD \\
\hline 58-46-SX-3-LP4 & 1.9 & 0.0 & 1.9 & 0.8 & 0.0 & 0.8 & -1.1 & 0.0 & -1.1 \\
\hline 68-26-SX-3-LP2 & 1.9 & 0.0 & 1.9 & 5.0 & 1.2 & 6.1 & 3.1 & 1.2 & 4.3 \\
\hline 51-41-SX-10-UP4 & 1.7 & 0.0 & 1.7 & 1.7 & 2.4 & 4.1 & 0.0 & 2.4 & 2.4 \\
\hline 61-21-SX-10-UP2 & 1.4 & 0.0 & 1.4 & 4.6 & 0.0 & 4.6 & 3.3 & 0.0 & 3.3 \\
\hline 58-65-SX-3-UP1 & 1.3 & 0.2 & 1.5 & 1.6 & 6.4 & 8.1 & 0.4 & 6.2 & 6.6 \\
\hline Total & 8.1 & 0.2 & 8.3 & 13.7 & 10.0 & 23.7 & 5.6 & 9.8 & 15.4 \\
\hline
\end{tabular}

Table 1 NPR-3 Historical Results from HEGF

\section{Well Selection Parameters}

The initial two wells selected for the HEGF tests included 63-TPX-10 and 25STX-23. The wells were selected on the following criteria:

- Behind the pipe reserves which had not previously been exploited

- Formation characteristics useful to HEGF techniques

Based on the testing results in well 63-TPX-10 and subsequent tool modifications, the second well candidate, 25-STX-23, was replaced with well 61A-3. The justification for the replacement will be discussed later in the paper.

\section{Well 63-TPX-10}

The overall production curve for well 63-TPX-10 is shown in Figure 1. The well was the most successful well of a 1996 drilling program with an initial production rate of 700 BOPD and 5000 BWPD. The well was completed in the Tensleep "B" sand. From 1996 to 2000, the well had declined from 700 BOPD to under 20 BOPD with an excess of 8000 BWPD. Cumulative production during this timeframe was $90,000 \mathrm{BO}$ and over 10,000,000 BBW.

The Tensleep is a strong water drive reservoir with vertical natural fractures being present. The Tensleep is also a low porosity sandstone with average reservoir properties shown in Table 2. 
The well was selected for testing based on the untapped potential of the Tensleep " $A$ " sand, the high reservoir pressure maintained by the water drive system, and the natural fracture system.

During drilling significant oil shows were encountered in the Tensleep "A" sand further substantiating the idea of untapped reserves. It has

\begin{tabular}{|l|}
\hline \multicolumn{2}{|c|}{ Table 2 } \\
\hline \multicolumn{2}{|c|}{ Formation Characteristics of Tensleep } \\
\hline Description $\quad$ Dolomite-cemented dunal sand. Two units \\
separated by 10 - 15 ft dolomite. Faulted \\
and fractured with active water drive \\
\hline Original Oil in Place, mmSTBO \\
Area, acres
\end{tabular}
been a common field practice not to fracture stimulate the Tensleep wells to prevent or limit the fluid produced from the natural fracture system and attempt to draw oil from the matrix system instead.

The technology of Western Technologies was seen as appropriate to reduce near wellbore damage, tap into the matrix oil, and limit the influx of water. Due to the high reservoir pressure maintained by the Tensleep/Madison aquifer, large fracture stimulations are typically not performed on the Tensleep. Small acid treatments for perforation and near wellbore cleanout are generally preferred.

\section{Testing Procedure}

The main objective of the HGEF testing in the Tensleep "A" sand was to compare the production and well productivity of the sand just after perforating with the production and well productivity after treatment.

Appendix A lists the daily field notes on the test. In summary, the following field activities occurred:

April 26, 2000 A cast iron bridge plug (CIBP) was set between the Tensleep "A" sand and the Tensleep "B" sand isolating the two horizons. Sand was then dumped on top of the CIBP to further mechanically isolate the sands. The Tensleep "A" sand was perforated with 4 shots per foot (4 SPF) from 5362 5392.

April 28, $2000 \quad$ Flow test at 108 barrels of water per day (BWPD) rate. No artificial lift used. Flow was into a 400 bbl tank on location.

May 5-12, 2000 Pump test of perforated Tensleep "A" sand with small submersible pump. Tests indicated 1,255 barrels of fluid per day with only a trace of oil. Tests confirmed by short tank tests into 400 barrel tank on location. Fluid level was 151 joints of tubing from surface or approximately $4,800 \mathrm{ft}$ down (See Figure 2).

May 16, 2000 First run of Western Technologies MicroFrac tools. Propellant contained in 2" PVC tubes. Three separate tubes connected with aircraft type cable. The casing collar locator $(\mathrm{CCL})$ was above the three tubes. 
After several runs up and down the hole to get the CCL operational, the tools were lost downhole. It appeared that the tools snagged on the wellhead coming out and the cable pulled out of the cap.

May 17, $2000 \quad$ Second run of MicroFrac tools. Propellant still contained within PVC tools. Overnight improvements included the use of higher temperature adhesive (bottomhole temperature $~ 200 \mathrm{~F}$ ), and 1/2" pipe connecting the PVC tube to the CCL, and a higher grain primer cord to burn through plastic tube used as a sheath. First run included one 10' tube with two 17" propellant charges. The first tool was fired with slight rocking of the wireline truck but no surface flow. Upon retrieval the PVC tube was gone, the $1 / 2$ " pipe lightly "egged", and the ignition cap fired. Second run included two- ten' PVC tubes joined by flexible rubber hose. The tool did not fire due to intermittent electrical ground on the ignition cap.

May 23, 2000 Third run with completely redesigned MicroFrac tools. Propellant contained within a 3-1/8" hollow steel carrier gun (See Figure 1). The propellant sections were 17" long separated by frac sand. The carrier gun had the equivalent of twelve shots per foot (12SPF) with aluminum port plugs over the propellant sections (See Figure 2). The tool fired on the second run with many of the ports perforated or blown out (See Figures 3 and 4). The sand inside the carrier gun appeared to be slightly crushed and several rows of steel port plugs below the propellant sections were perforated or blown out - an indication of the energy expended by the propellant.

Recent data (1) from other DOE testing operations has shown that bottomhole pressures in excess of 15,000 psi can be generated for a few milliseconds with no increase in surface pressure. Well 63-TPX-10 also did not show any surface flow. See Appendix A for detailed field notes.

After the stimulation treatment, the small submersible was run again. Stabilized pumping tests indicated 2.9 BOPD and 3650 BWPD - a three-fold increase in production. Of more importance, the fluid level was approximately 694 feet from surface a vast improvement over the unstimulated condition. The prior fluid level was 4,800' from surface. Based on the above, the well productivity increased from .24 BFPD/ft of drawdown to $5.1 \mathrm{BFPD/ft}$ of drawdown resulting in a twentyfold improvement in fluid productivity (See Figure 2).

Based on the increased productivity of 63-TPX-10, the pump was now in a strong upthrust condition. Based on the potential for pump wear and possible failure, the well was shut-in at this point. Field production operations at NPR-3 were encouraged by the results and were instrumental in budgeting a rerun of the original large submersible pump to determine if additional oil could be produced (See Figure 3).

From July, 2000 through December, 2000, Well 63-TPX-10 was able to produce an average of 12.7 BOPD and 7,730 BWPD. The fluid level dropped to 69 joints from surface or 2,170 feet. The calculated productivity index declined from 5.1 to 3.6 BFPD/ft of drawdown; however, the productivity index was still a factor of fifteen (15) better than the unstimulated condition. The decreased productivity 
index may also be due to the non-linear nature of pressure drops in the system and not to the effects of the HEGF technique.

The above results assume that no damage has occurred to the cast iron bridge plug, casing, or other mechanical factors which would cause the Tensleep "B" sand to influence the results. One justification for non-damage is the speed at which the stimulation occurs. The high pressure pulse generated last for only $1 / 100^{\text {th }}$ of a second.

\section{Modified Well Selection}

The original second well candidate, 25-SHX-23, was a fractured shale candidate with 4-1/2" casing. Normal completion techniques for the Steele and Niobrara fractured shales at NPR-3, are openhole completions to allow the natural fractures to drain into the wellbore. A few select wells have been cased and cemented over the years, 25-SHX-23 was one of them.

Well 25-SHX-23 had very good shows of oil and gas while drilling with oil being produced at surface. The well was cased with 4-1/2" casing and cemented. The well was then perforated and attempted to be fracture stimulated which resulted in a partial screenout of the job. Significant oil reserves were thought to be behind pipe where a near wellbore technique such as HEGF may contact. Unfortunately, with the revised design of the MicroFrac tools with 3-1/8" carrier guns, inadequate clearance between the guns and the casing inner wall was present. Based on the clearance, a new well candidate search selected 61-A-3 as a replacement wellbore.

Well 61-A-3 was selected based on several critieria. Historically, the well had been a very good producer in the Second Wall Creek formation. From June, 1977 to July, 2000 the well had produced 261,000 barrels of oil. The second highest cumulative producer, out of two hundred in the Second Wall Creek formation. In addition, the well had an estimated additional ten (10) feet which had not been perforated which could yield additional reserves. The well also had a very small original fracture stimulation with only 5,000 lbs of sand. The Second Wall Creek is a sandstone formation. Average reservoir pressure is approximately $125 \mathrm{psi}$ at a depth of 3,000 feet. The low reservoir pressure is indicative of the stripper wells found at NPR-3 and was seen as one of the drawbacks of using this well. 
Production Baseline

Several years of recent production tests for Well 61A-3 are shown in Figure 4. The well had declined to approximately $1-2$ BOPD and $10-30$ BWPD. The main objective of the HGEF testing in the Second Wall Creek sand was to compare the oil production of the sand after reperforating and stimulation with the prior production.
Table 3

\begin{tabular}{|lr|}
\hline \multicolumn{2}{|c|}{ Table 3 } \\
\hline \multicolumn{2}{|c|}{ Formation Characteristics of Second Wall Creek } \\
\hline Description $\quad$ Shallow offshore bar sand grading downward \\
into shale. Faulted and fractured. \\
\hline Original Oil in Place, mmSTBO \\
Original Gas in Place, mmSCF \\
Area, acres & 57.1 \\
Average Porosity, \% & 3590 \\
Average Permeability & 15 \\
Average Net Thickness, feet & 100 \\
Reservoir Pressure, psi & 30 \\
Depth, feet & 125 \\
Reservoir Temperature, deg F & 2900 \\
Oil Gravity & 125 \\
\hline
\end{tabular}

To estimate an exact production level prior to the stimulation, one $400 \mathrm{bbl}$ production tank was moved on location. Figure 5 shows the baseline production from July 6, 2000 to July 17, 2000. The baseline production was 20 barrels of fluid per day (BFPD) with an oil cut of $.5-3 \%(.1-.6$ BOPD ).

\section{Testing History}

Appendix B lists the daily field notes on the test. In summary, the following field activities occurred:

June 29, $2000 \quad$ The well was reperforated from 2,996 - 3,006 ft and 3,015 3,040 with four shots per foot (4SPF). The initial completion was one (1) shot per foot (1SPF). New perforations were added from 3,040 - 3,050 (ten feet with 4SPF). This new interval was believed to contain some additional new reserves.

July 27, $2000 \quad$ Start water injection into well to create a positive fluid level $(1,500$ feet minimum over tool). Due to low reservoir pressures in the Second Wall Creek, producing wells are pumped off with no static fluid level above the perforations. Western Technologies indicated that a minimum of 1,500 feet of fluid above their tool was desirable. A water feed line was laid to the well to facilitate the temporary water injection.

August 9,2000 Cumulative water Injection at 9:30 am - 29,618 barrels of water. First propellant gun run by wireline subcontractor (See Figure 5). Fluid level approximately 135 feet from surface. BOP on well (See Figure 6). First gun centered over 3,040 - 3,050. Fired propellant. Line jumped 6" briefly. Shot under lubricator with valves open. No fluid signs at surface. Lost $1^{\text {st }}$ gun in the well (fish). Casing Collar Locator (CCL) came out of hole.

The wireline subcontractor ran the second tool in the well (See Figure 7). Second gun centered from $3,026-3,032$. The propellant tool fired successfully. The wireline moved $2-3$ inches - not as much as first run and the tool was recovered successfully. Three propellant sections were used for each tool for a total of six sections. 
Figure $8-11$ show the second tool after retrieval. The pictures illustrate some of the downhole energy generated by the rocket propellant. The aluminum and sometimes steel port plugs are perforated or blown out of the tool. Additional rows of plugs as shown between Figure 7 and Figure 11 are affected. These rows are not directly across from the propellant section but below the section. The tool is similar in appearance to the effects seen using a high gram perforating charges.

\section{Post Stimulation Production Analysis}

Figures $6-7$ show the production results after stimulation. The total fluid increased to approximately 120 barrels of fluid per day (BFPD) or six-fold. The increase in total fluid production, however, is clouded by the injection of water that was necessary to create a positive fluid head of 1,500 feet in the wellbore. See Figure 8 for the injection rate and pressure into the low pressure reservoir.

At the end of the injection volume of approximately 30,000 barrels, the surface wellhead injection had risen to slightly over 50 psi. Falloff tests indicated that sufficient volume had been injected to allow the testing to proceed without a large drop in fluid level inside the casing.

No increases in oil production were seen either from the new ten (10) foot perforated zone or the reperfed interval.

\section{Conclusions}

RMOTC has assisted an industrial client in developing their technology for high energy gas fracturing to a commercial level. The modifications and improvements implemented during the technology testing process are instrumental in all field testing efforts at RMOTC.

The importance of well selection can also be critical in demonstrating the success of the technology.

To date, significant increases in well productivity have been clearly proven in well 63-TPX-10. Gross fluid production was initially raised by a factor of three. Final production rates increased by a factor of six with the use of a larger submersible pump. Well productivity (bbls of fluid per foot of drawdown) increased by a factor of 15 to 20 .

The above results assume that no mechanical damage has occurred to the casing or cast iron bridge plug which could allow well production from the Tensleep "B" sand.

In the case of well 61-A-3, a six-fold increase in total fluid production was seen. Unfortunately, the increase is clouded by the water injection into the well that was 
necessary to have a positive fluid head on the propellant tool. No significant increase in oil production was seen.

The tools which were retrieved from both $63-\mathrm{TPX}-10$ and $61-\mathrm{A}-3$ indicated a large amount of energy, similar to high gram perforating, had been expended downhole upon the formation face.

Reference 1 Pulse Fracturing Tests Show Mixed Results

Oil and Gas Journal · December 6, 1999 
Appendix A 


\section{Well 63TPX10}

\section{Appendix A}

Field Notes

\section{$5 / 26 / 00$}

Test Meters@ @-TP-10

3735 BW and 3.1 BO in 24 hrs @ 65 HZ

Fluid level @ 22-23 joints

$625 \mathrm{BW} X .4 \mathrm{BO}$ in $4 \mathrm{hrs} .=156.25 \mathrm{Bbls} / \mathrm{hr}$.

1407 BW X 1.0 BO in 9 hrs. $=156.33 \mathrm{Bbls} / \mathrm{hr}$.

Fluid level@22-23 joints

\section{$5 / 25 / 00$}

Test Meter @ B-TP-10

1891 BW/080 in 14 hrs. @ 58 HZ= 135 Bbls/Hr. = 3242/Day

Fluid level@ @ 21 jts from surface.AZero@meters.

176/168/178 Amps - 419 Volts.

Increase freq. To $60 \mathrm{HZ} ; 186 / 1768 / 187$ Amps - 434 Volts

300 BW/.380 on meter, F.L. still @ 21 jts from surface

Increase freq. To $62 \mathrm{HZ} ; 195 / 186 / 195$ Amps - 448 Volts

445 BW/.5BO on meter, Fluid level @ 22 jts.

Increase freq. To 65 HZ; 210/202/211 Amps - 470 Volts Max. freq. On Centrilift paperwork.

680 BW/.8BO on meter $=235$ Bbls/1.5 hr= 156.67 Bbl/hr. @ 65 HZ; 210/201202/210 Amps - 469 Volts

1220 BW/1.3 BO on meter = 775 Bbls $/ 5$ hr. = 155 Bbls/hr. Fluid Level @ 22-23

jts.

$1455 \mathrm{BW} / 1.5 \mathrm{BO}$ on meter

$855 \mathrm{Bbls} / 6.5 \mathrm{hrs}=155.4 \mathrm{Bbls} / \mathrm{hr} .=3729 \mathrm{Bbls} /$ Day

210/201-202/210 Amps - 469 Volts

Fluid Level @ 22-23 jts from surface.

\section{$5 / 24 / 00$}

Well still dead, slight vacuum.

Centrilift spooler/operator \& ESP technician on location. P.U. and service motor, attach Apothead@and motor lead. Unchain dual seal sections from derrick leg and inspect: pull seal plugs, seal oil clean, no contamination, top off seals with new oil. All pump and bolt to seal sections. Band motor lead with protect to seals and pump. Start RIH w/2 7/8" tbg @ 8:20AM, 159 jts in hole by 10:35 AM. Pack off Huber ESP wellhead, install wellhead manifold. Rig Crew had to shut down@ 11:30 AM to go into Casper for respiratory Fit Test and General Physicals. Lunch. Gather parts for wellhead flow manifold, so we can connect hose and pump kill fluid to the tank. Fluid level @ 8 jts down. 
Start E.S.P @ 12:56 pm, pumped up in 1 minute, $52 \mathrm{HZ}$, going into $400 \mathrm{Bbl}$ tank, starting tank gauge 2'8", 30 psi wellhead

2 PM T.G. 9' 52 " = 125.54 BW/hr $=3013$ Bbl/Day, recover Kill wtr.

2:30 PM T.G. 12 ' 92 " = 133.6 Bbl/hr= $3206 \mathrm{Bbl} /$ Day, $200.4 \mathrm{Bbls}$

3:00 PM: T.G. 15' 11" = 125.25 Bbl/hr = $3006 \mathrm{Bbl} /$ Day, $265.53 \mathrm{Bbls}$

3:15 PM: T.G. 17' 22 ", switch well to FWKO @ B-TPX-10, 52 psi wellhead.

5:00 PM: Put well on test, 127 BW/hr. @ 7 PM, fluid level @ = 19 jts.

8:00 PM: Go to $58 \mathrm{HZ}$, fluid level @ 21 joints = $141 \mathrm{Bbl} / \mathrm{hr}=3390 \mathrm{Bbls} /$ Day.

\section{$5 / 23 / 00$}

$\mathrm{RIH}$ w/redesigned Microfrac tool.

Petrolog truck still on location. PU redesigned propellent tool: $22.5^{\prime}$ x $31 / 8^{\prime \prime}$ steel carrier with six 17" propellent charges separated by fine frac sand. Port plugs over propellent are aluminum with steel port plugs between charges, 12 SPF with 1 " port plugs. (5 2 ' from middle of CCL to top of $1^{\text {st }}$ propellent charge, $23^{\prime}$ to top of $6^{\text {th }}$ charge). Length from middle of CCL to end of tool is 27'.

$\mathrm{RIH}$ under lubricator/packoff on BOP. Correlate to upper 20' of $A \mathrm{~A} @$ sand perfs (5362'-82'), CCL @ 5357.5", 5.5' above top of $1^{\text {st }}$ propellent charge @ 5363', bottom of $6^{\text {th }}$ charge @ 5381'. Attempt to fire tool, did not fire, POH, check ignition cap - OK, but bad connection on cap. Run back in hole, recorrelate, fire tool @ 11:10 AM, CCL quit working, POH with tool, tool did fire, as part plugs were missing or perforated where the charges had been. The steel carrier was not distorted, but the frac sand between the charges was crushed and compacted such that the charges must have moved down a few inches inside the carrier. This was also indicated by a row or two rows of perforated steel port plugs below each charge. Perf @ort plugs had round 2 " holes. NOTE: No blow @ surface when tool fired, fluid level @ 210' from surface. Rig crew removed BOP and flange and set on BOP trailer. Installed Huber ESP wellhead, installed tbg sub w/valve, packed off wellhead. S.I. well.

Notes: Plastic AO@inged port plugs failed pressure testing @200 psi and were not used. Aluminum port plugs were used over the propellant.

Notes: The bottom $10 \mathrm{ft}$ of the tool ( 3 charges) had 44 port plugs missing and 42 port plugs with 2 " perforated holes.

The upper $10 \mathrm{ft}$ of the tool ( 3 charges) had 60 port plugs missing and 31 port plugs with 2 " perforated holes.

\section{$5 / 17 / 00$}

$1^{\text {st }}$ Run: Petrolog truck still on location. RIH under lubricator/pack off with 10' PVC tube containing two 17" propellent charges w/sand between the charges. This Amicrofrac@tool had better glue for the PVC end - caps (high temperature adhesive) and 2 " line pipe connecting the tube (PVC) to the CCL and Agnition@ cap to Avaterproof@he propellent charges and 80 grain primer cord. (Note: primer cord used on Tues. 5/16 was 25 grain). Previous primer cord did not burn through plastic tube covering it.

Correlate to lower $10^{\prime}$ of $A$ @sand perfs 5382'-92'. AFire@he propellent charges, no blow @ surface, truck rocked slightly. POH, 10' PVC tube gone, ignition cap 
fired, Aegged@ine pipe connection indicated that the propellent charges did ignite and burn (Per Joe Butcher of Petro-Log)

$2^{\text {nd }}$ Run: PU double (tandem) 10-12' PVC tubes joined by flexible rubber connection (rubber hose w/clamps), two 17" propellent charges/tube, four charges total for this tool. RIH under lubricator/packoff. Correlate to upper 20' of AA @sand perfs 5362'-82'(20'). Attempt to fire this tool, no ignition, ignition cap has intermittent electrical Aground.@POH to inspect ignition cap - looks ok. Run back in hole w/tool, still have intermittent electrical Aground@ $\mathrm{POH}$, put tool back on truck. Close BOP to shut well in. SDFN @ 4:30 PM. Note: extremely rain/muddy!

\section{$5 / 16 / 00$}

Petrolog on location. Run in hole with three Microfrac tools hung together with airplane type cable. Petrolog made three runs up and down the hole trying to get the casing collar locator (CCL) to work. The CCL tool was sized for smaller casing. Last run out of the hole the tools snagged on the wellhead and fell off the CCL.

\section{$5 / 15 / 00$}

Kill well with 178 Bbls of 9.8 ppg salt water (4 loads), rig hand drove pressure truck. Flow meter on truck was not correct due to bad wire. Dan Kelly repaired meter. Salt water (Nacl) came from the WTF. Nipple down wellhead manifold and pump tee, unpack wellhead. RU centrilift spooler (Kim). POH with 159 jts 2 $7 / 8 "$ tbg, ESP, and flat lead sheathed cable.

Lay down motor and pump on sills on ground, chain the dual seal assembly to the derrick leg. Install tbg sub w/valve in the wellhead, pack off wellhead, shut well in SIFN@ @ 6 pm.

Note: John Schmill (Centrilift Technician) supervised the disassembly of the E.S.P

\section{$5 / 02 / 00$}

MI Centrilift spool truck \& ESP trailer.

P.U. and assemble ESP - stand back, chain to derrick leg.

R.I.H. with 5 stds of $27 / 8$ " (10 jts), POH, laydown 10 jts on trailer, now have 158 jts (79 stands) in derrick, fluid level $\sim 42$ joints from surface - oil on 52 of the 10 jts laid down. Install pothead on motor and flatlead.

Start in hole with 2 7/8" tbg, 4 bands/jt, 26 stands in the hole @ 10:45 AM. Ran total of $159 \mathrm{jts}+6^{\prime}$ sub, length 5025.86 . Pack off wellhead, install flow tee, tighten flow/dc(?) Connections

Start ESP @ 2:45 pm, tbg press 50 psi, F.L. @ 3 PM @ 49 jts, F.L. @ 100 jts @ 4 PM, @117 jts@4:30 PM, @124 jts@5 PM. Pump went down@ @:15 PM on underload.

159 jts $27 / 8^{\prime \prime}-5019.86^{\prime}$

(4' sub) - 6' sub - 6.0'

Pump - 13.40' Pump intake @ 5039.26'

Twin Seals - 12.60'

Motor - 14.80' 
TOTAL - 5066.-66' Bottom of Motor

\section{$5 / 01 / 00$}

Flow well, initial tbg press $100 \mathrm{psi}$, csq $70 \mathrm{psi}$, made $4.5 \mathrm{BF} / \mathrm{hr}$, skim - 1/4\% oil. Pump 67 Bbls 10\# brine to kill, 30 Bbls down tbg, 37 Bbls down backside, tbg on vacuum, but backside flowing.

Get more brine, pump 29 Bbls down backside, killed well. Total kill vol. 96 Bbls $10 \#$ brine.

PQH with 50 stands $27 / 8$ tbg, laid down 4 jts on trailer, also laid down 1 stand from other side of tubing board. Have 84 stands (168 jts) in derrick, will set pump @ 5300' at 167 jts + 40' ESP.

Rig down BOP and load on trailer, install swedge w/valve on casing. Shut well in SDFN.

\section{$4 / 28 / 00$}

Casing press $70 \mathrm{psi}$, the press $70 \mathrm{psi}$, Open well to pit, started flowing, switch well to tank, flowed 3.3 BF $1^{\text {st }}$ hour. Flowed $42.79 \mathrm{BF}$ in $9.5 \mathrm{hrs}$, avg rate 4.5 $\mathrm{BF} / \mathrm{hr}$. Oil cut ranged from a skim to $1 / 4 \%$ until $11 \mathrm{AM}$. From 11 AM-4:30 PM, no visible oil cut. Rig crew moved 42 tongs/slips off location.

Note: Backside pressure dropped from 70 psi to 10 psi by $10 \mathrm{AM}$. Had intermittent flow (slugs of gas) from 9:45 AM-11 AM, than steady flow rest of day from 11 AM-4:30 PM.

Shut well in @ 4:30 PM, closed T.I.W. valve, pipe rams closed on BOP, SDFN.

\section{$4 / 26 / 00$}

Run in hole bit and scraper 174 jts total

joints $=5492.23$ ' $(5502.23 \mathrm{~KB})$

Ran in with sand line and bottom mandrel measuring and marking sand line.

Moved in $400 \mathrm{Bbl}$ swab tank

$\mathrm{P} 00 \mathrm{H}$ w/TBG, scraper and bit

Rig up Atlas Wireline to set CIBP and perf. Tensleep A @sand.

RIH w/CIBP, tagged fluid at 500;=set CIBP @ 5410', dump bail 2.5 sacks sand on bridge plug.

AA @Sand - perf 5362'-5392' w/4 SPF tag sand at 5403'

Rig down Atlas tagged sand @ 5403'

Rig Down loggers

Got rental TIW valve from Graco

\section{$4 / 25 / 00$}

Load TBG on trailers $27 / 8$ " workstring.

P.U. and RIH w/bit and scraper on $27 / 8$ " tbg

\section{$4 / 24 / 00$}

Move Casing off location and install BOP

Too muddy to haul in work string.

Load workstring on trailers. 


\section{$4 / 18 / 00$}

Blade location

MIRU W/O rig. Pipe racks, wooden sills

Dug 10 bbl pit

Kill well w/NaCl from WTF, approx. 10 ppg, 70 bbls down annulus and 50 bbls down tubing

Uncap well, Rig up spool truck, cut off excess cable laying on ground, rack had fallen over previously.

Set sills w/forklift. Spotted in chemical truck to rinse pipe while pulling.

Pull 4.5" casing, 3.5" tubing and cable. Separated 20' and 40' joints of casing.

Note: the 4.5" casing wall is very thin and the pin ends rolled under when laying down. Suggest inspection and to re-running.

One minor repair to cable will be required on cable lead and armor repair.

Pull motor, seal and pump. Slight wtr in upper seal, pure oil in bottom seal.

Pump and motor ok.

Cap well in for night.

Note: A rental BOP and accumulator and a rental scraper w/bit sub are on location but have not yet been used. The well was pulled without BOP, stayed dead, would have been extra time stripping BOP over cable. 
Appendix B 


\section{Appendix B \\ Field Notes}

\section{Well 61-AX-3}

\section{$06 / 28 / 00$}

R.U. Key Well services. $\mathrm{POOH}$ w/pump \& 3/4" rods. $\mathrm{POOH}$ with $27 / 8$ " tubing, Tubing anchor, SN, MA.

\section{$06 / 29 / 00$}

R.U. Petro-Log. Reperf Intervals 3015'-40' \& 2996'-3006' @ 4spf, 3 gun runs. Add Perfs 3040'-3050' @ 4spf, 1 run.

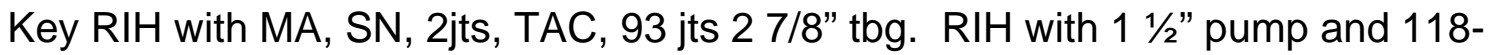
$3 / 4$ " rods, hang well on.

\section{7/21/00 (Friday)}

Injection Test

Jim M. loaded tank with approx. 260 BW (3 loads)

\section{7/22/00 (Saturday)}

R.U. fittings and hose to annulus, close valve to the V.R.U., start injection test: approx. $260 \mathrm{BW} / 2 / \mathrm{hrs}$ approx. $130 \mathrm{BW} / \mathrm{hr}=2.17 \mathrm{Bbls} / \mathrm{min}$.

\section{7/24/00 (Monday)}

Fluid Level @ 92 jts (30 psi S.I.)

Fluid Level @ 2920', 76' Above top perf @ 2996' \& 130'

Above btm perf@ 3050'

2 7/8" tbg string: 1-6', 1-10' subs, 93 jts, TAC, 2 jts, SN, MA

Perf 2996' - 3006'; 3015' - 3050'

(135' of fluid in hole)

Approx 10:00 am. MIRU Key Well Service. POOH with rods and pump and laydown. SDFN.

Per Ralph S.

(2:45 pm) Pull and lay down, move 400 / $300 \mathrm{Bbl}$ tank to location. and fill with tensleep or Madison water.

Fill 400 and $300 \mathrm{Bbl}$ tanks. 


\section{7/25/00 (Tuesday)}

POOH with 2 7/8" tbg, 6'. 10' sub, SN, MA.

Laydown on sills. Mount our 7 5/8" Larkin "K" flange and Graco B.O.P., jump start accumulator and pressure-up, close blind rams to shut well in, RDMO.

\section{7/27/00 (Thursday)}

Begin water injection.

\section{8/07/00 (Monday)}

Cum Injection: 26,278BW

\section{8/09/00 (Wednesday)}

Cum Injection @ 9:30 am: 29,618BW

Propellant job with Petrolog ran two "Propellant" guns (approx. each @ 17' long). Fluid Lever approx. 135' f/surface. (Graco BOP on well). First gun centered over $3040-3050$. Fired propellant. Line jumped 6 inches briefly. Shot under lubricator with valves open. No fluid signs at surface. Lost $1^{\text {st }}$ gun in the hole (fish). CCL came out of hole. RIH with $2^{\text {nd }}$ propellant gun. Second gun centered from $3026-$ 3032. Fired "OK". Line moved $2-3$ inches not as much as first shot., recovered successfully.

Note: No rig on well, used Petrolog's mast truck. RDMO Petrolog.

Note: Propellent (6 sticks) supplied by Western Technology - Microfrac, used 3 sticks per gun.

\section{8/23/00 (Wednesday)}

MIRU WO-2 to fish "lost" propellant gun. Awaiting fishing tools. Nipple down Graco B.O.P. and remove our 7 5/8" Larkin "K" flange, set B.O.P. on accumulator trailer

\section{8/24/00 (Thursday)}

TIH with Graco fishing tool (17.80'), tag (fish) with jt \#96 approx. 15' in air, (calc. tag approx. 12' in air (above G.L.) came down, rotate string with wrenches, tag again (hard) approx. 9' above G.L., rotate down 2' - 3', (harder rotation) (catch fish?)

10:30 am - 11:30 am - POH with 2 7/8' tbg and fishing tool, $\underline{\mathrm{NO} F I S H}$, Nㅡ fluid on tbg

12:30 pm - RIH for second fish attempt, tag again approx. 16' (1' higher than previously) in air tag hard, torques hard with hand wrenches or power tongs, pick up on tbg 3'-4', "drop" string quickly, then run jt \#96 down to 2' above slips, pickup 5', rotate down to right, pull I jt, have drag - "feels like" fish. 
1:45 pm - TOH with 2 7/8" tbg and fishing tool, NO FISH, again SDFN.

NOTE: Cut lip guide has some marks on outside edge, "looks like" we were sitting on top of fish, no "swallow" 


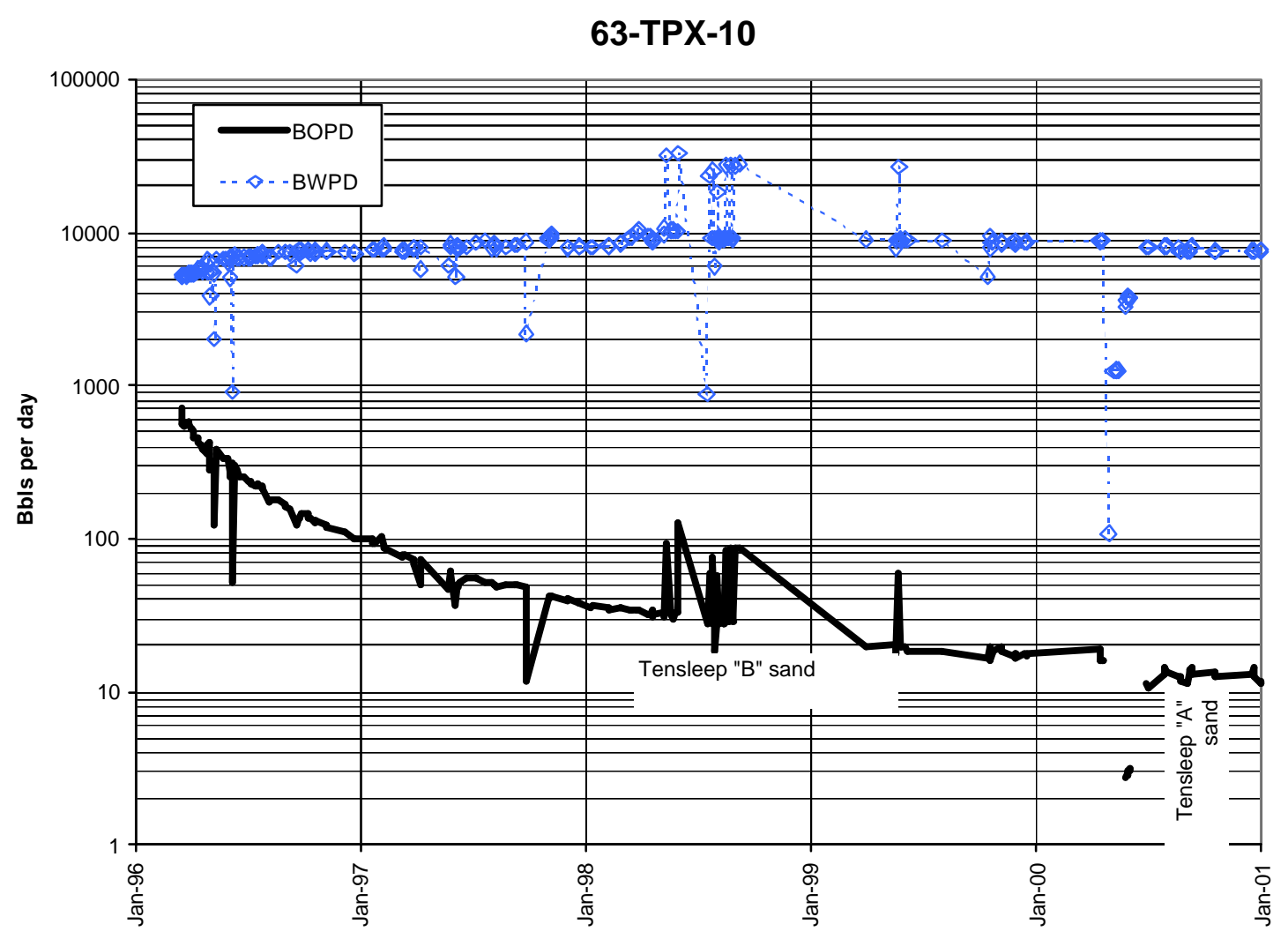

Figure 1. Well 63-TPX-10 Production History. MicroFrac Stimulation performed in May, 2000.

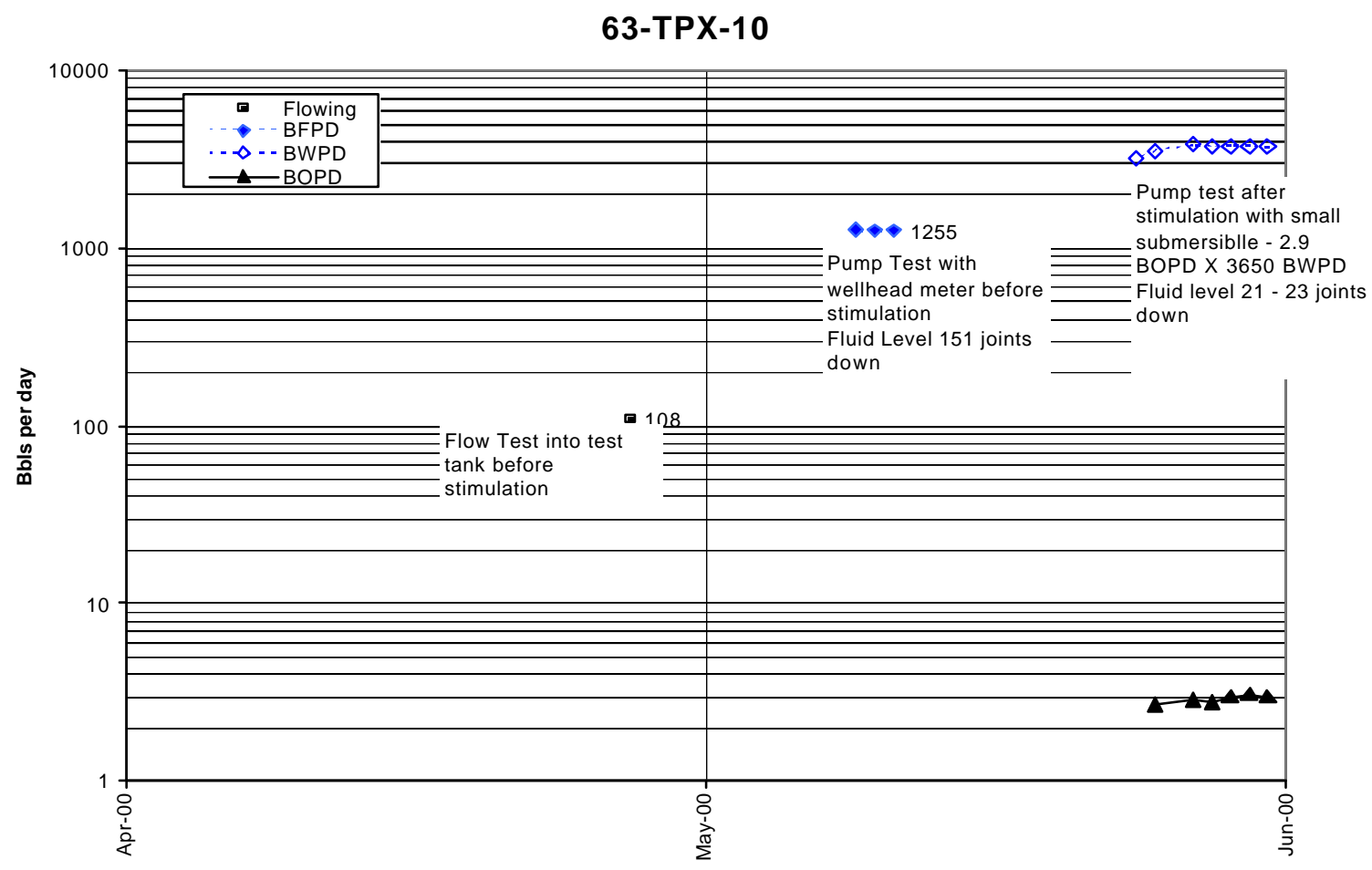

Figure 2. Well 63-TPX-10 Production Comparison: Flow Test after Perforating but before Stimulation; Pump test after perforating but before stimulation; and Pump test after stimulation. 
63-TPX-10

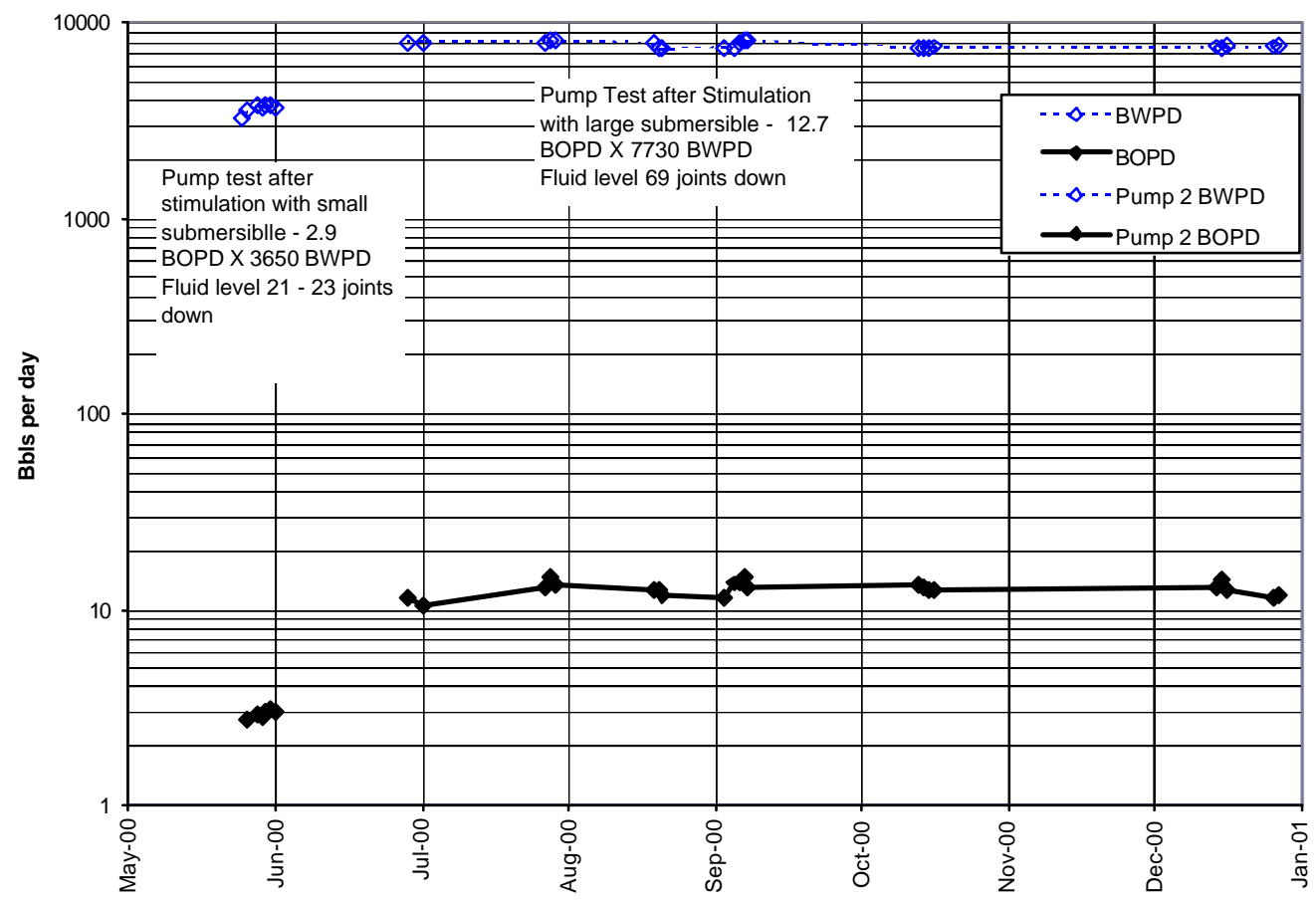

Figure 3. Well 63-TPX-10 Production Comparison: Pump test after stimulation with small submersible; Pump test after stimulation with large submersible.

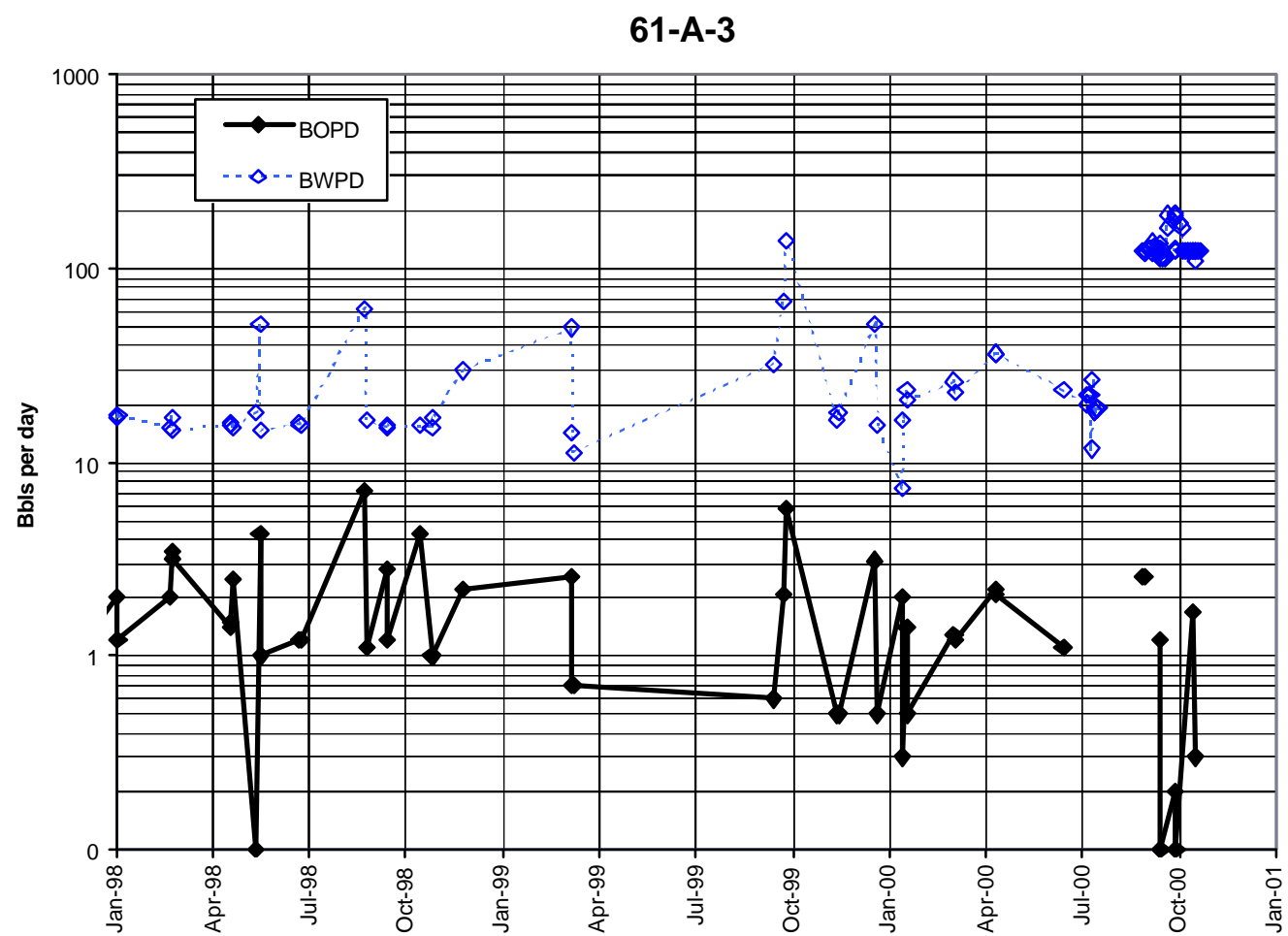

Figure 4. Well 61-A-3 Production History. MicroFrac Stimulation performed in August, 2000. 


\section{$61-A-3$}

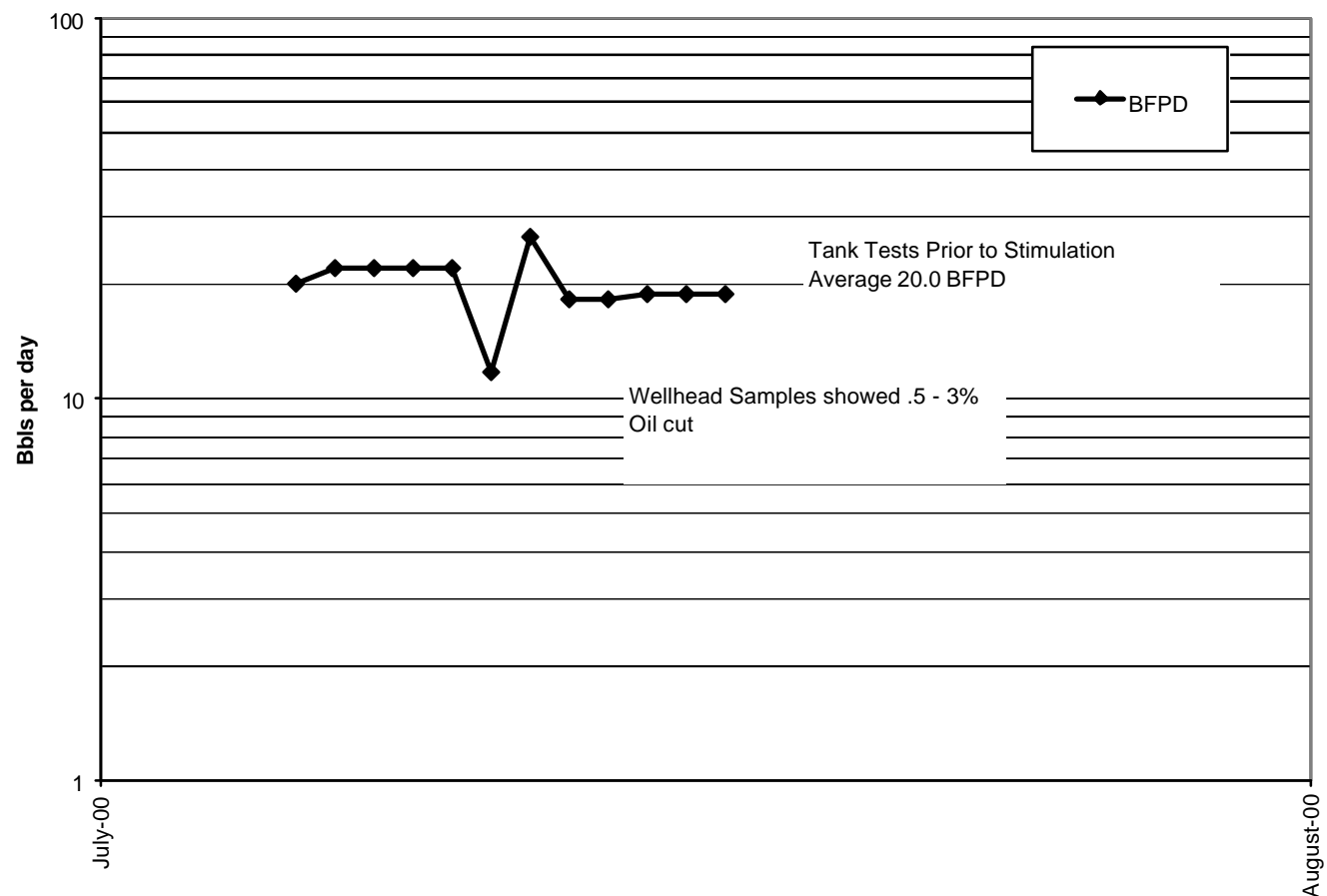

Figure 5. Well 61-A-3 Baseline Production Prior to stimulation (tank tests.)

61-A-3

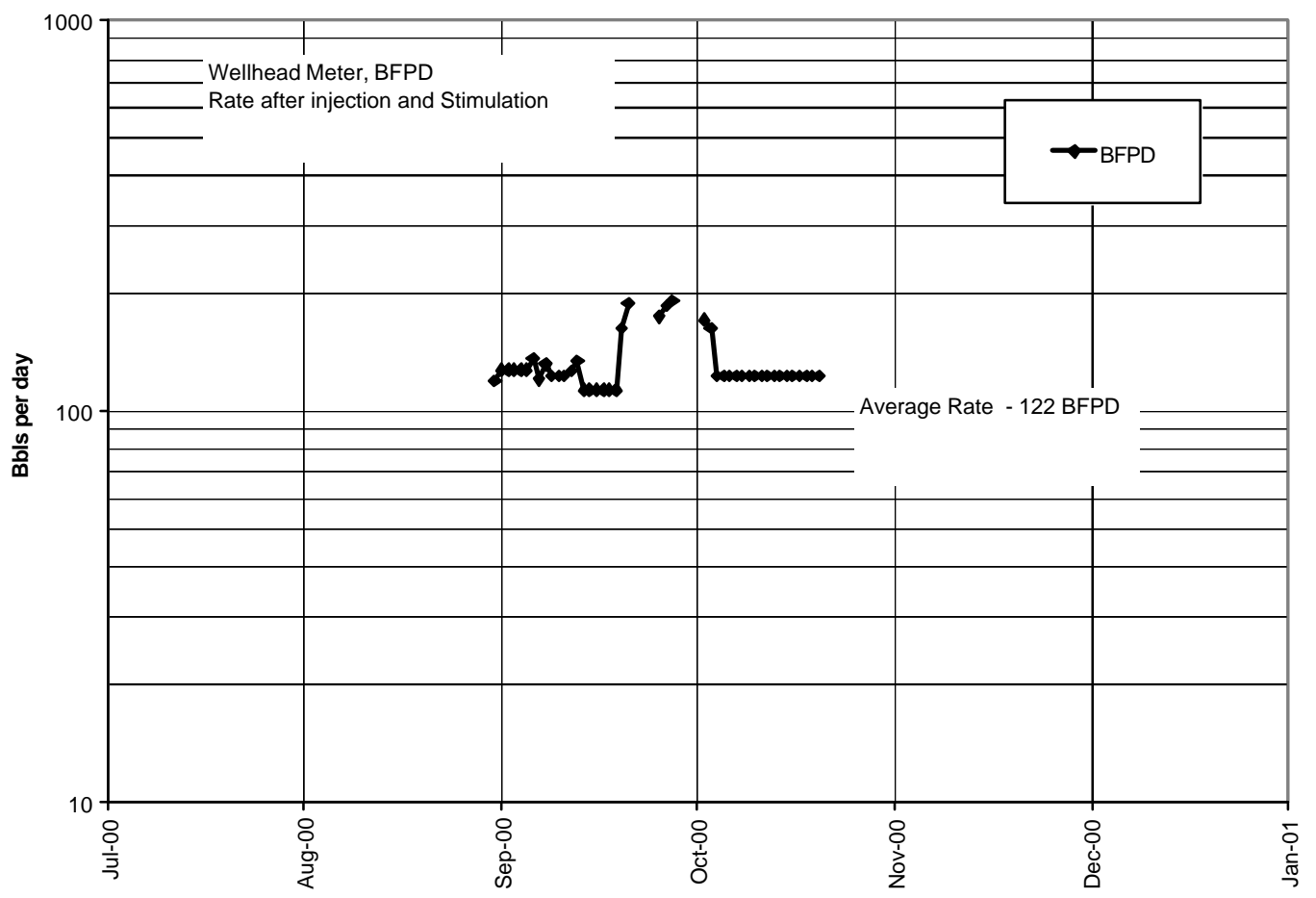

Figure 6. Well 61-A-3 Production Rate after stimulation and injection. Rates through wellhead meter. 


\section{$61-A-3$}

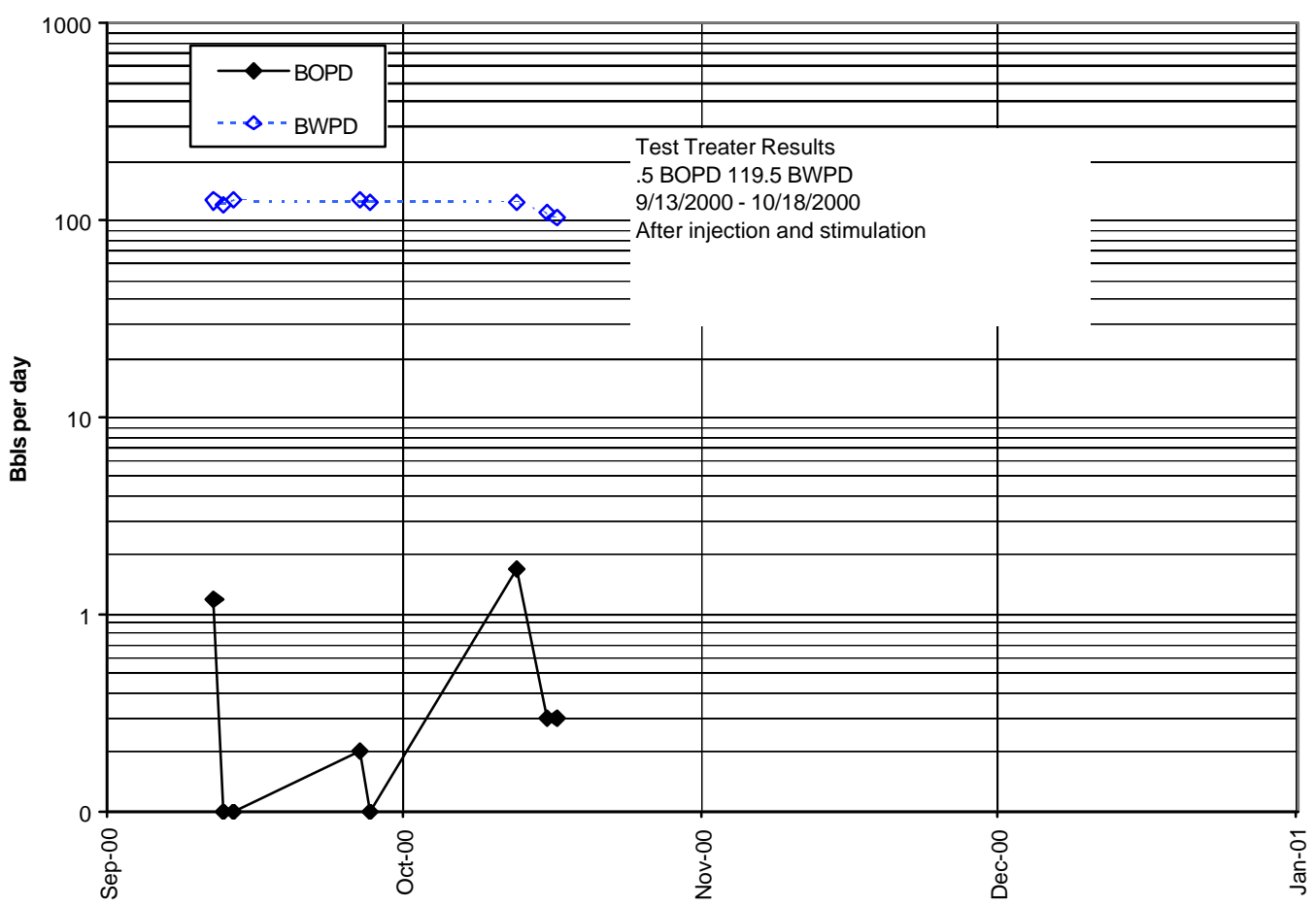

Figure 7. Well 61-A-3 Test Treater results after stimulation and injection.

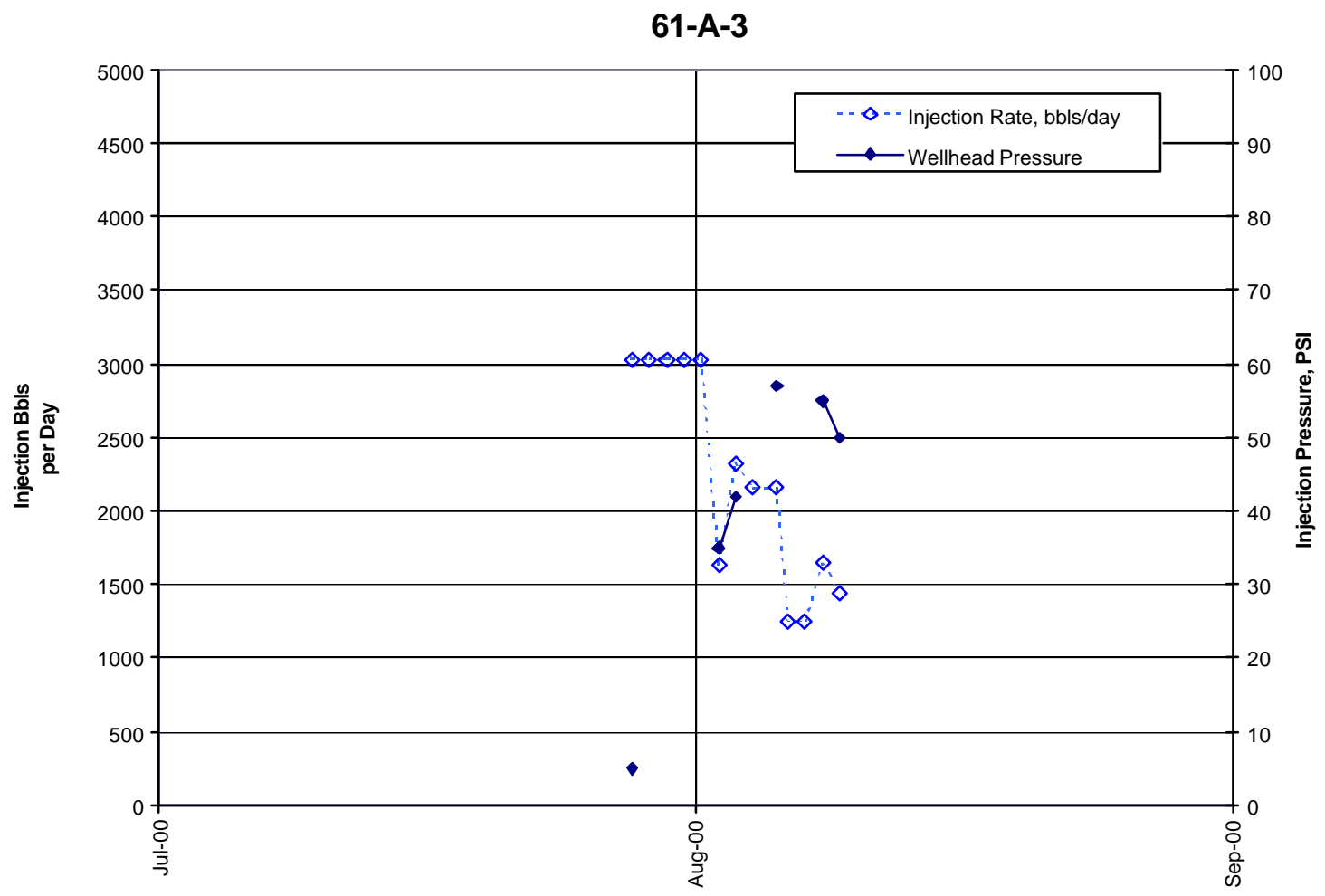

Figure 8. Well 61-A-3 Injection rate and pressure necessary to maintain fluid head above tool. 


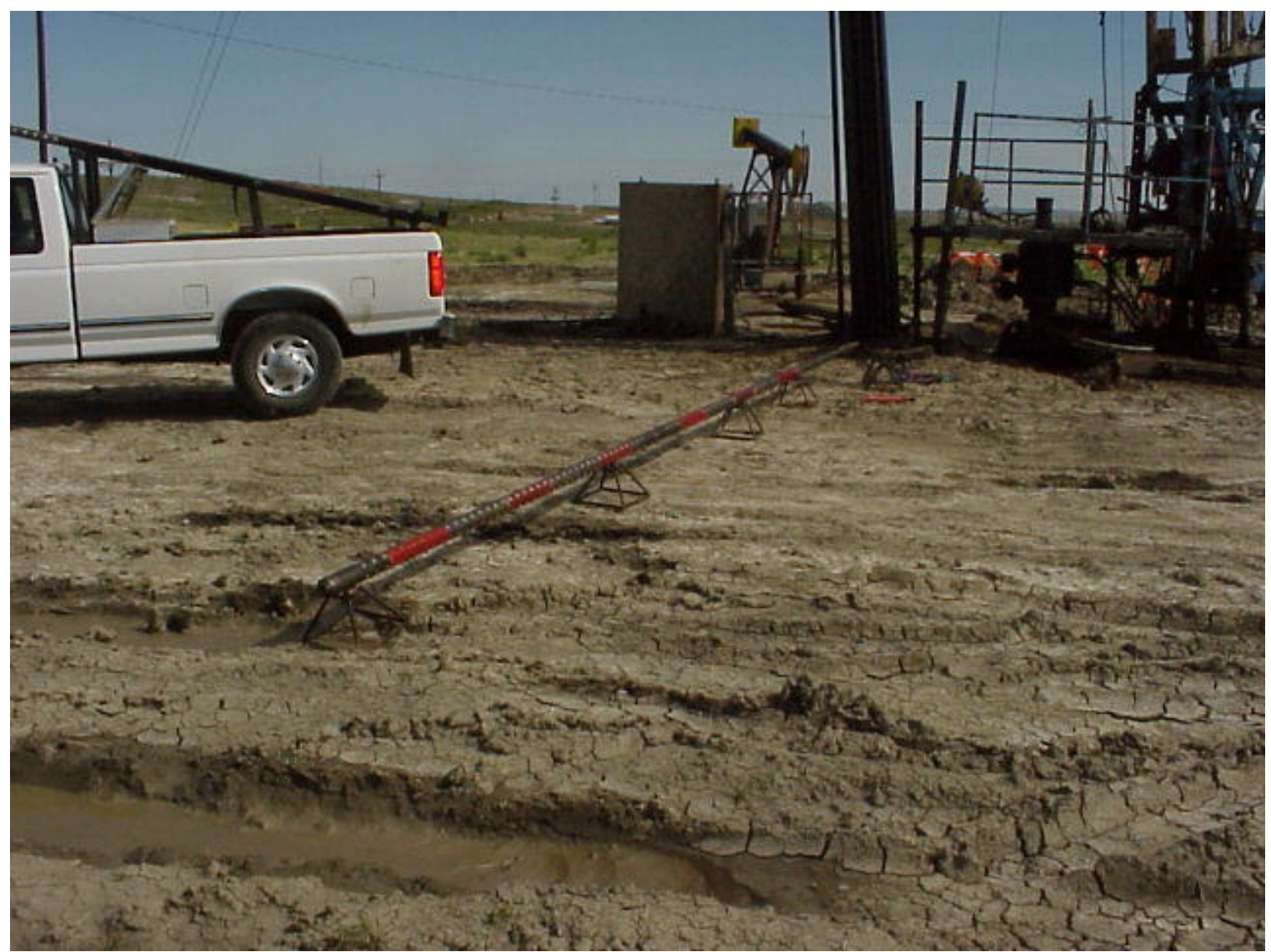

Picture 1. Well 63-TPX-10. Redesigned MicroFrac tool. Red (dark) areas on tool are propellant sections. Tool had six propellant sections.

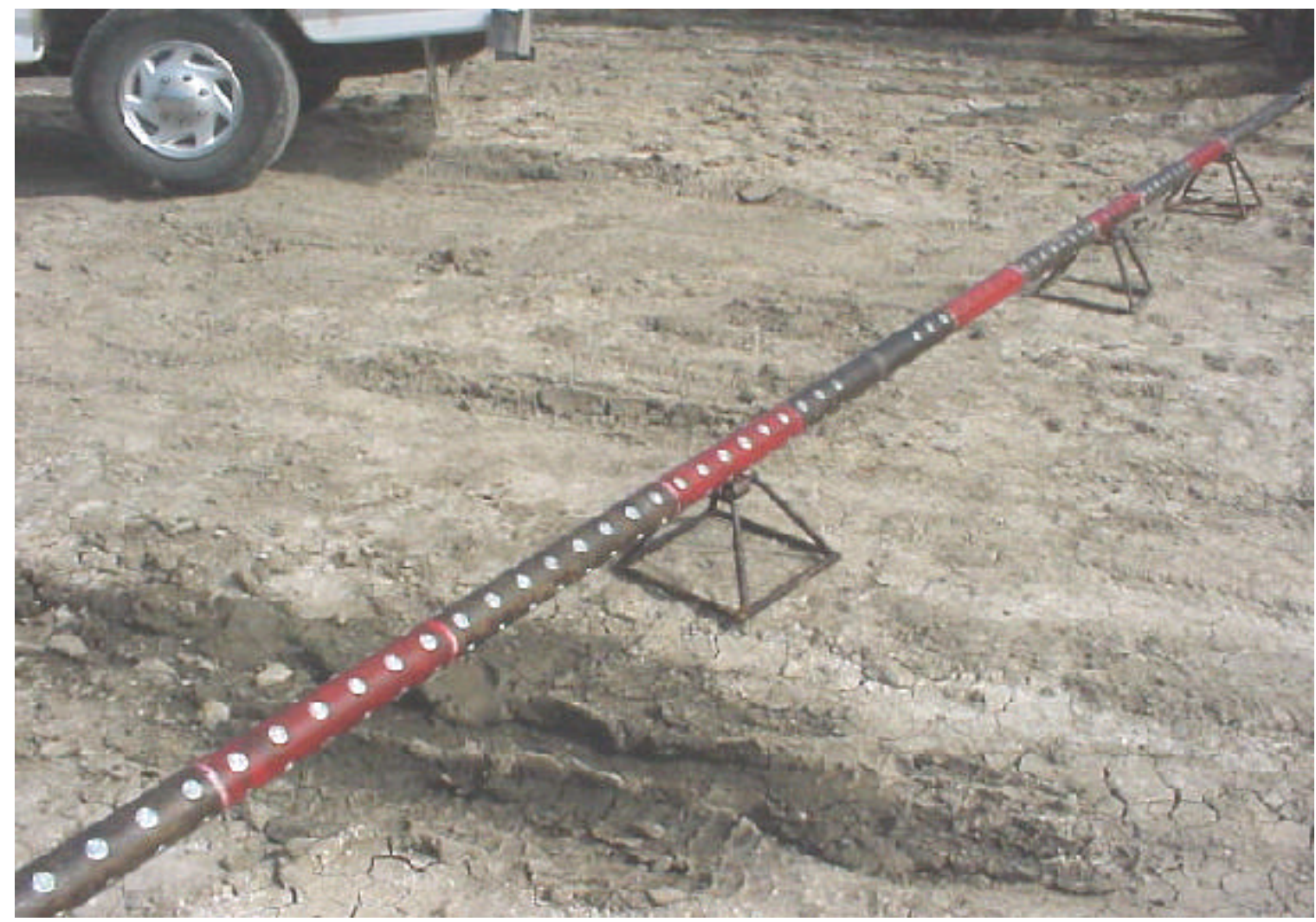

Picture 2 Well 63-TPX-10 closeup of the tool showing aluminum port plugs over propellant sections. 


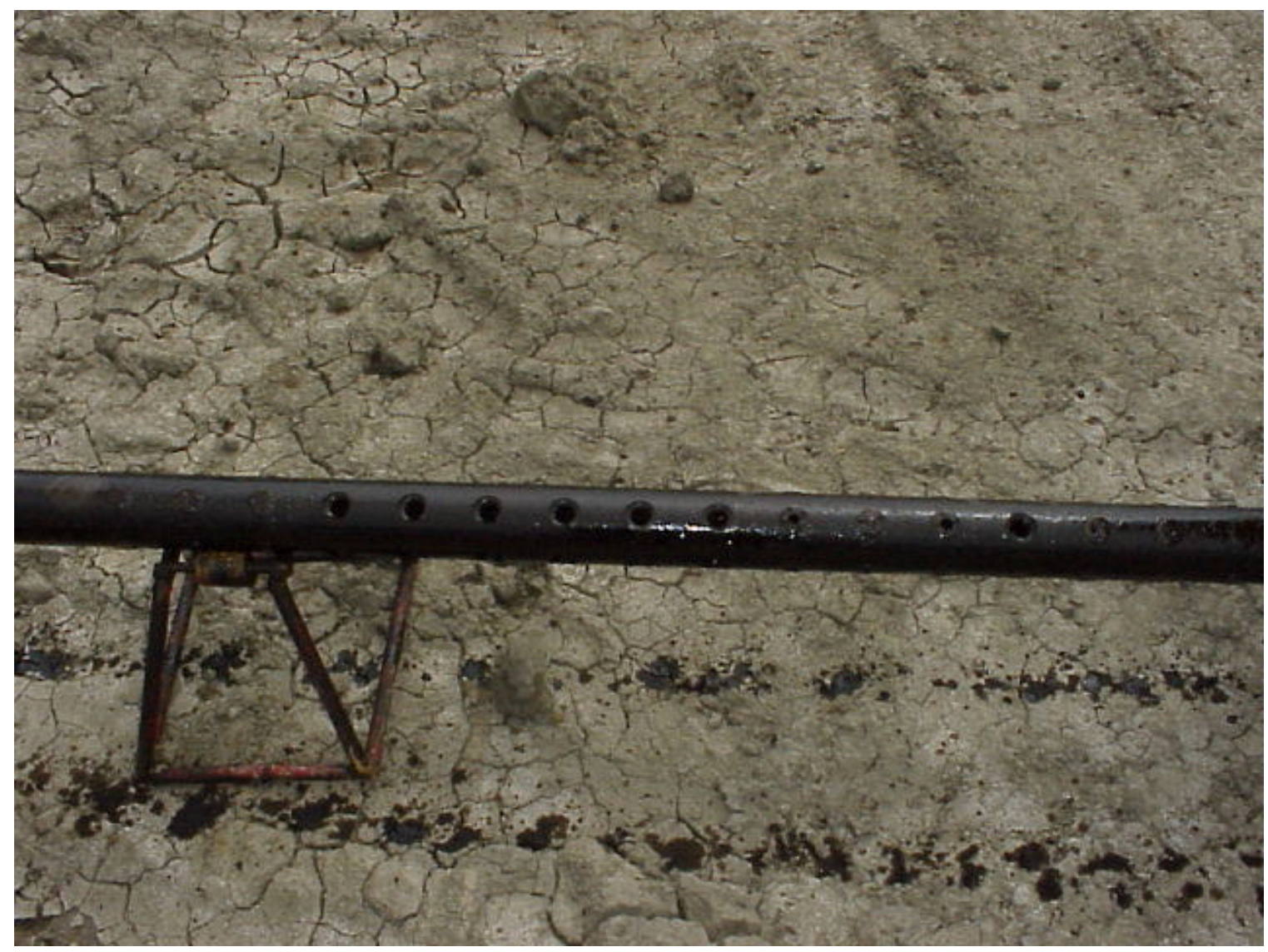

Picture 3. Well 63-TPX-10. Retrieved tool showing results of ignition. Note varying size of perforated plugs with some blown out.

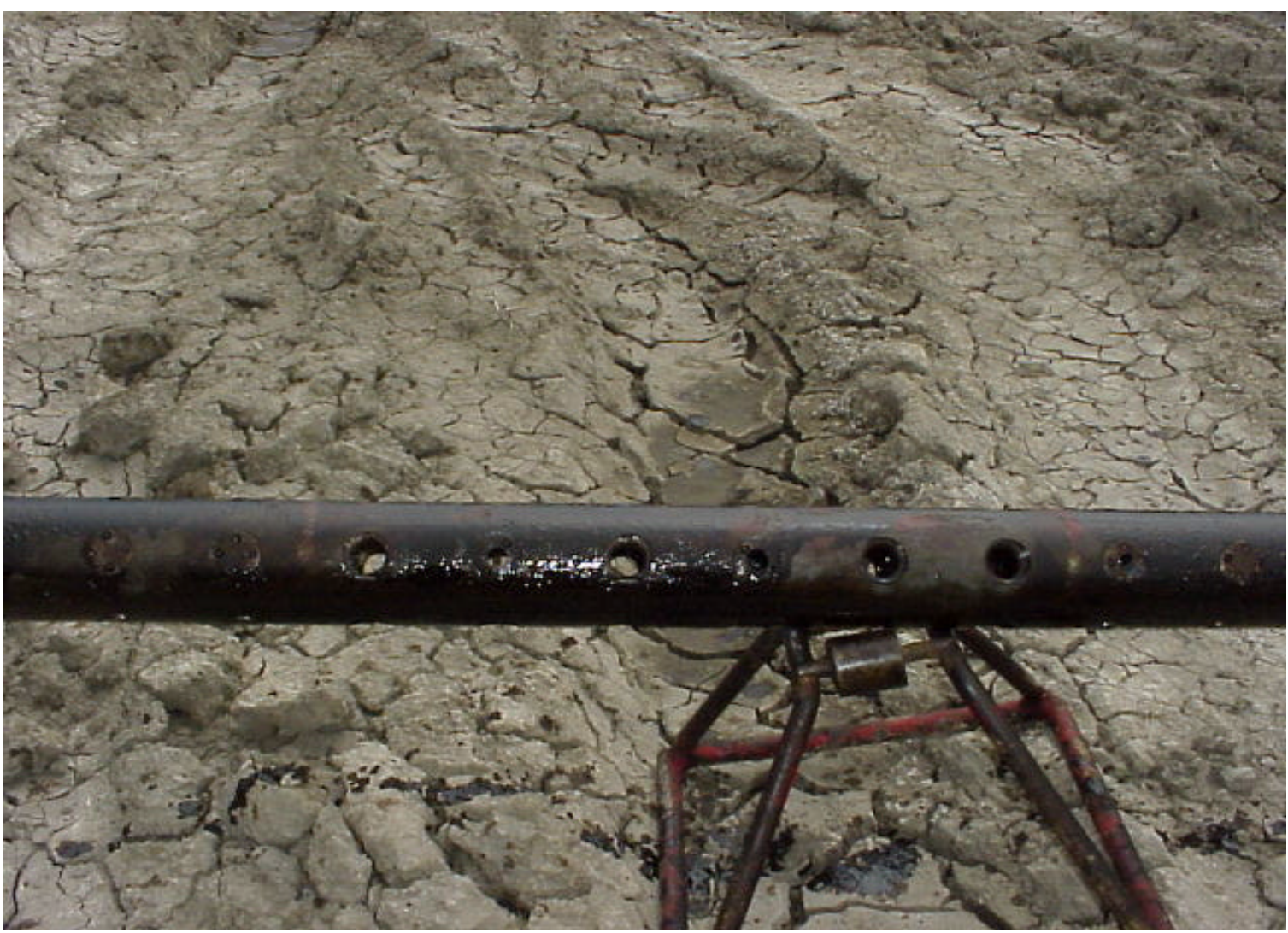

Picture 4. Well 63-TPX-10. Additional close-up of MicroFrac tool results. 


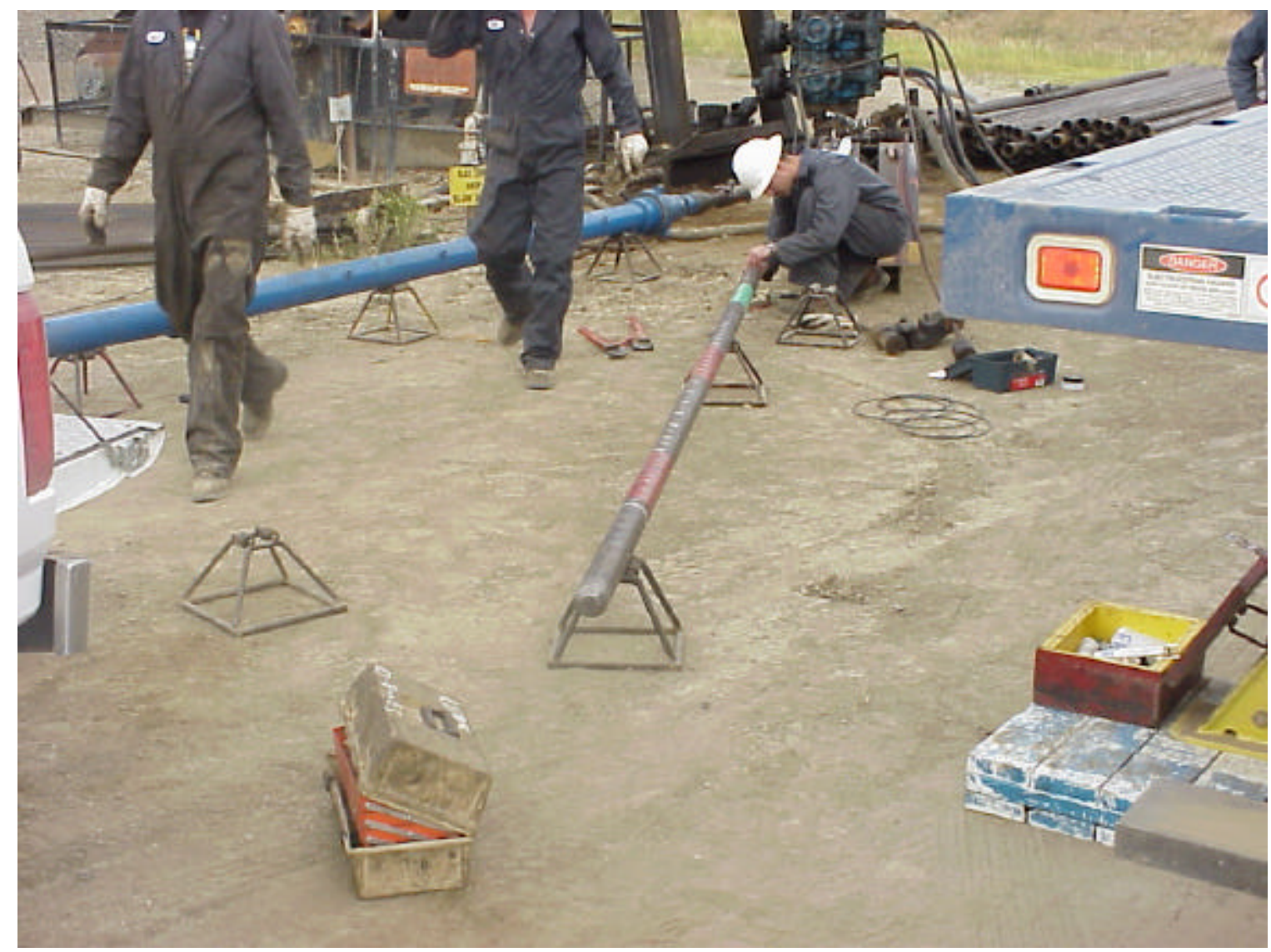

Picture 5. Well 61-A-3. First tool on second well shown being prepared for firing.

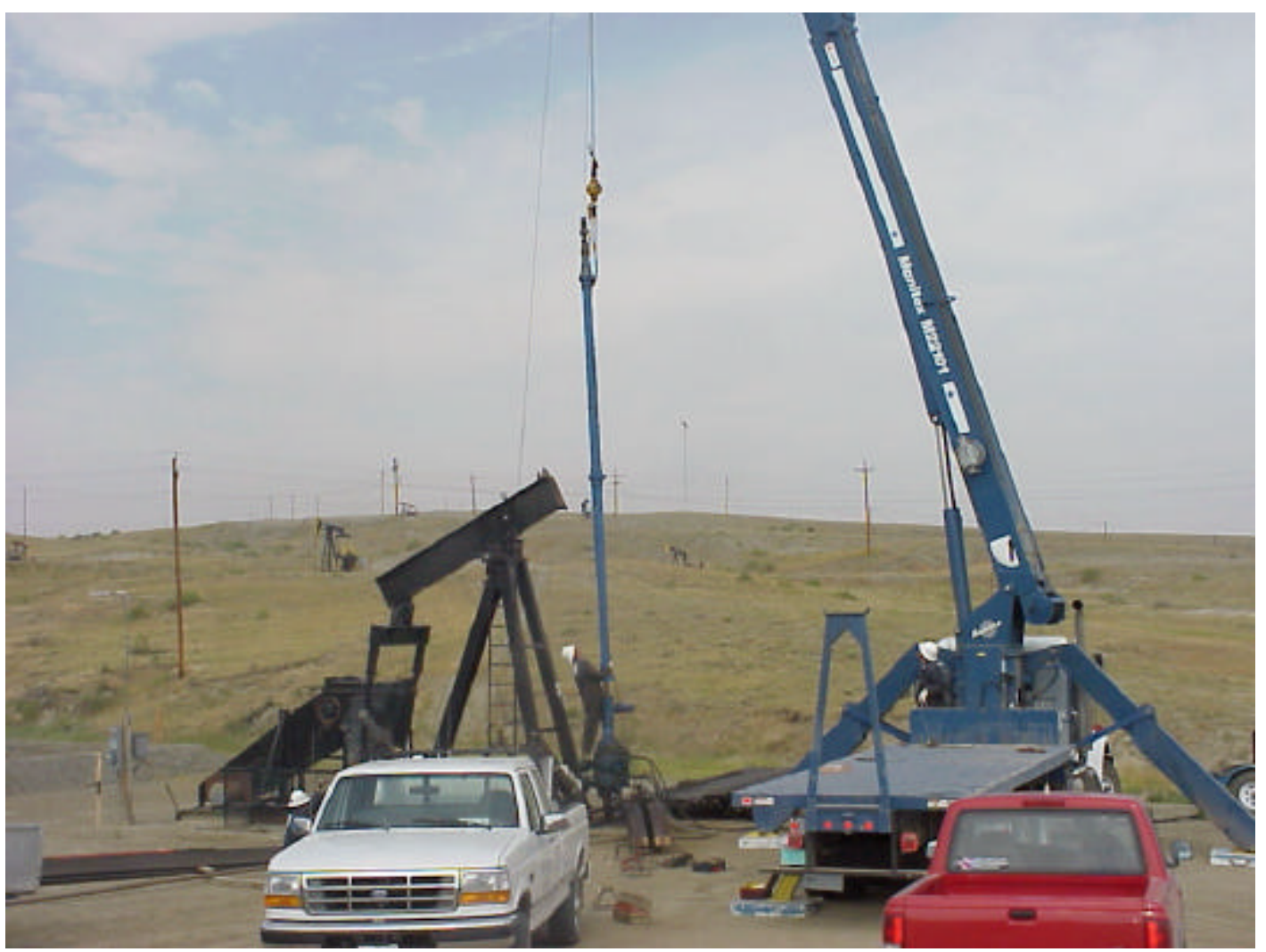

Picture 6. Well 61-A-3. First tool being lowered inside wellhead lubicater and BOP equipment. 


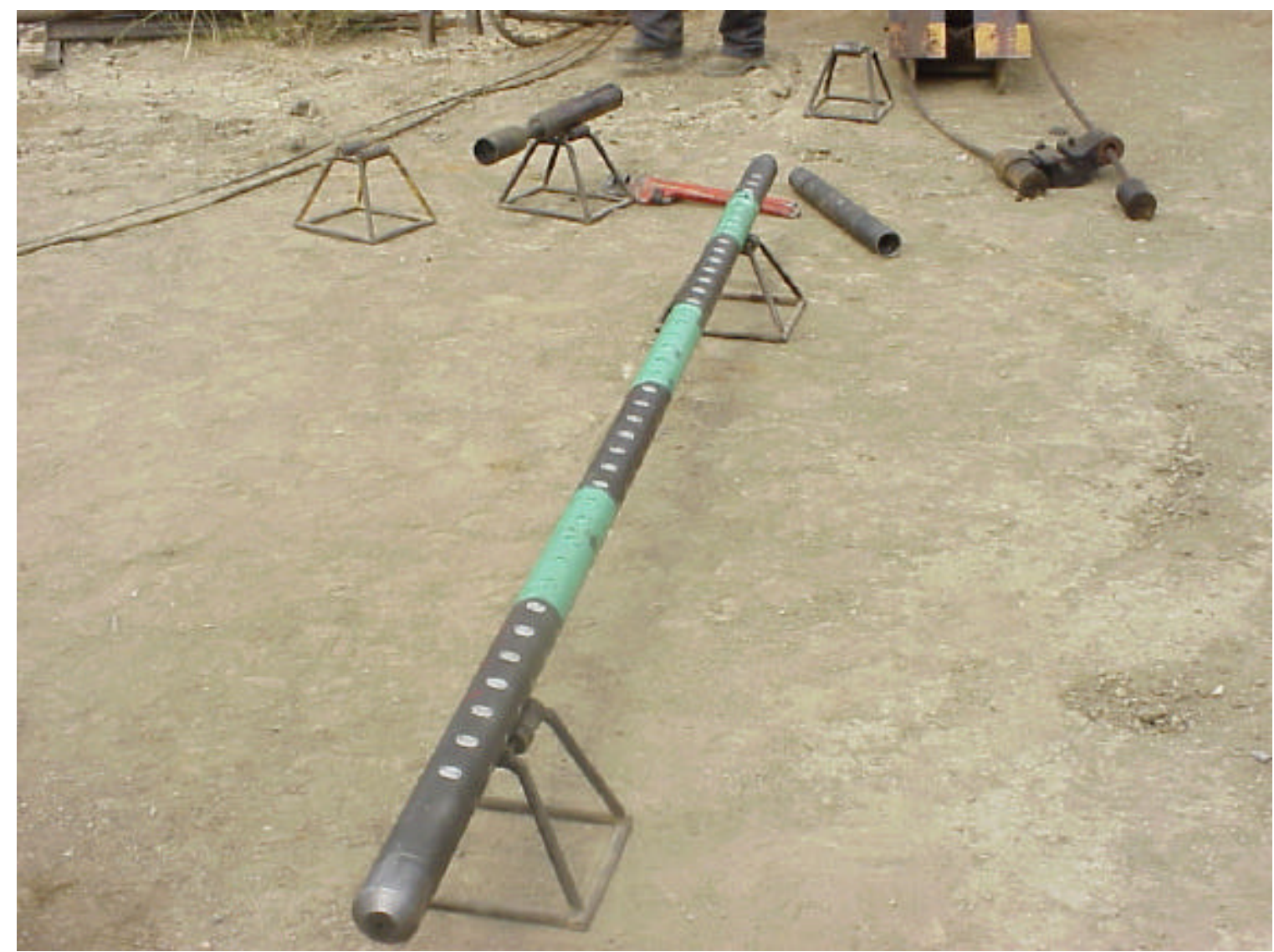

Picture 7. Well 61-A-3. Second tool being prepared for stimulation. First tool lost downhole.

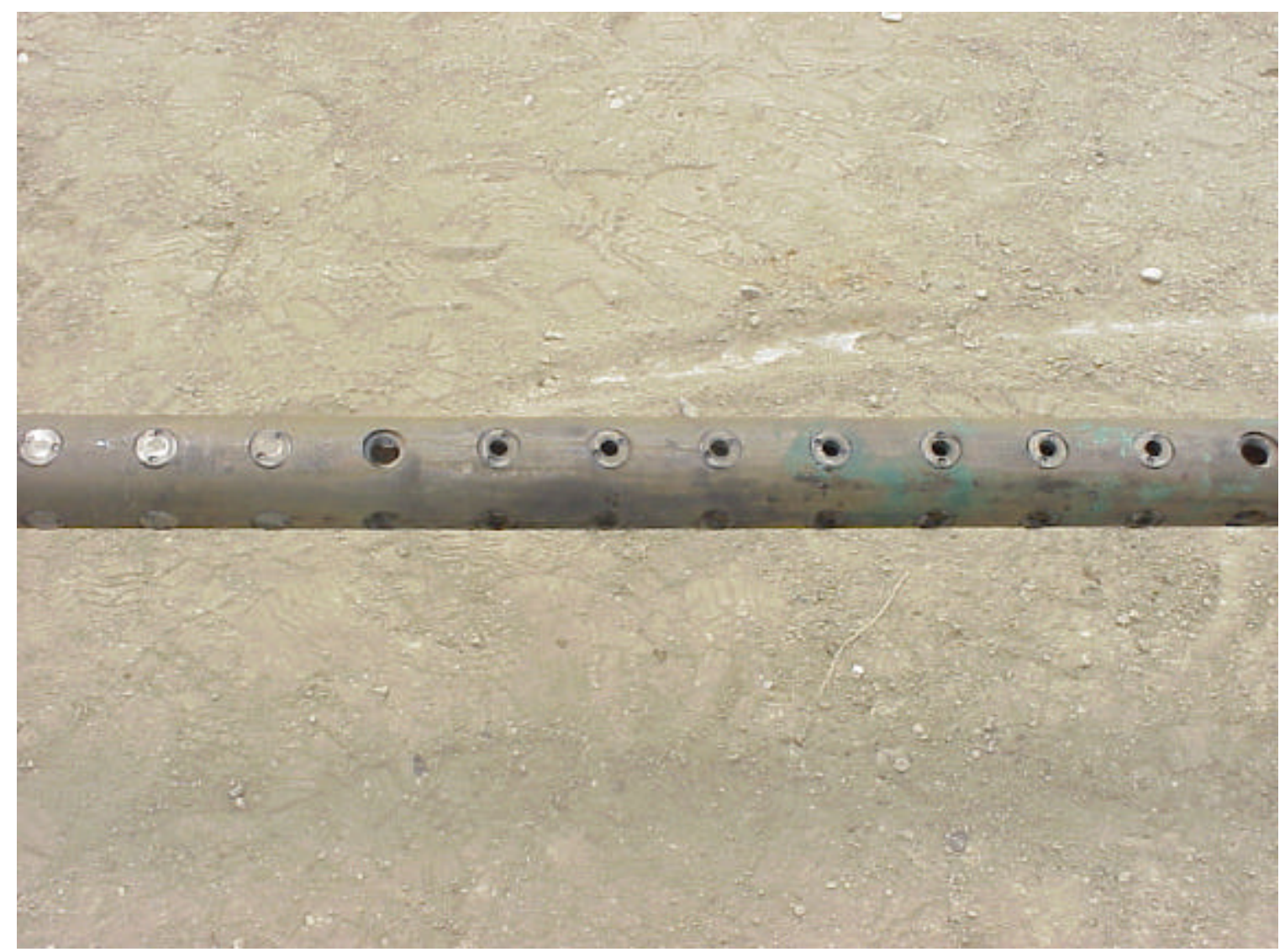

Picture 8. Well 61-A-3. Second tool retrieved. 


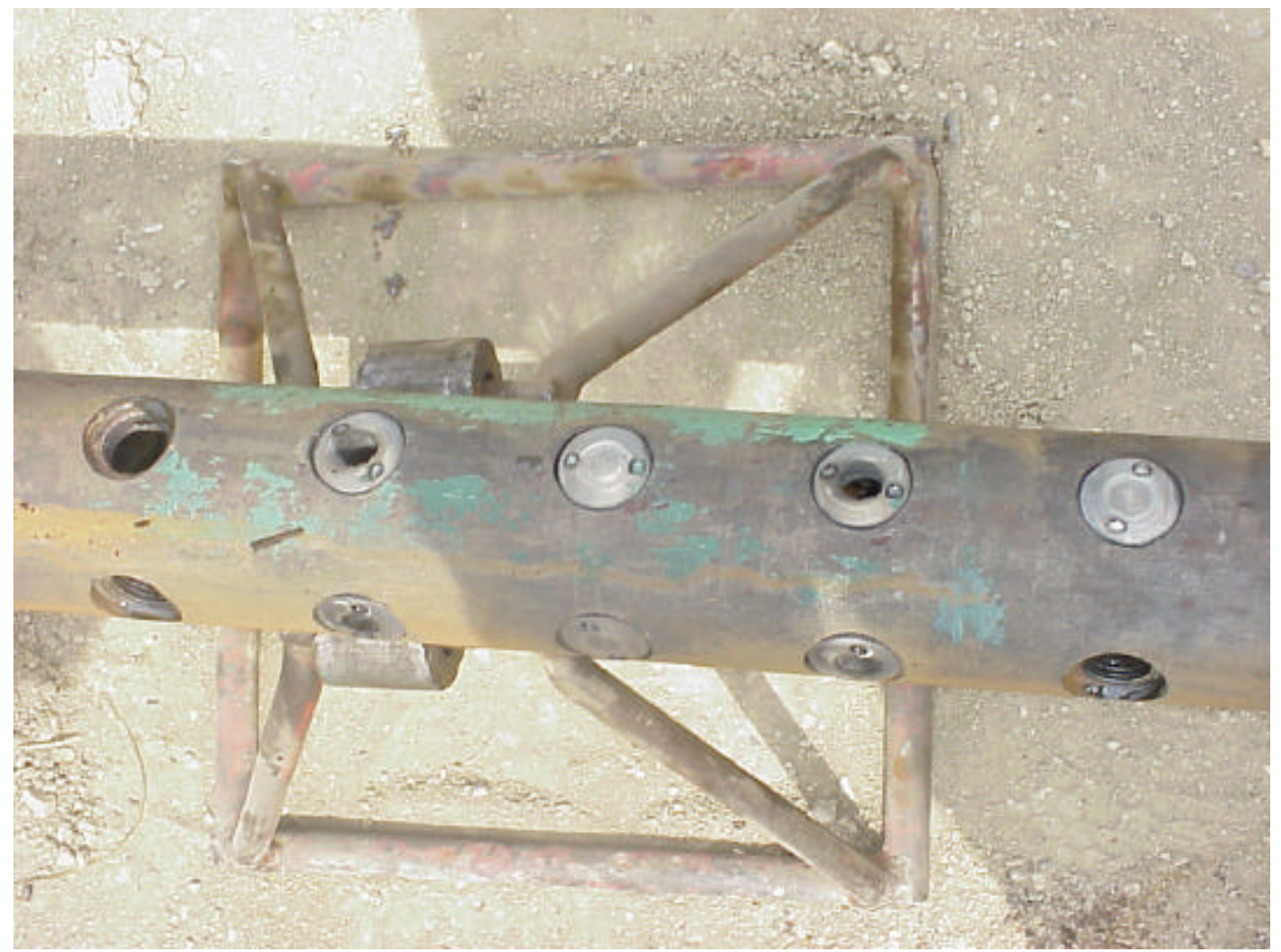

Picture 9. Well 61-A-3 Closeup results of second tool retrieved.

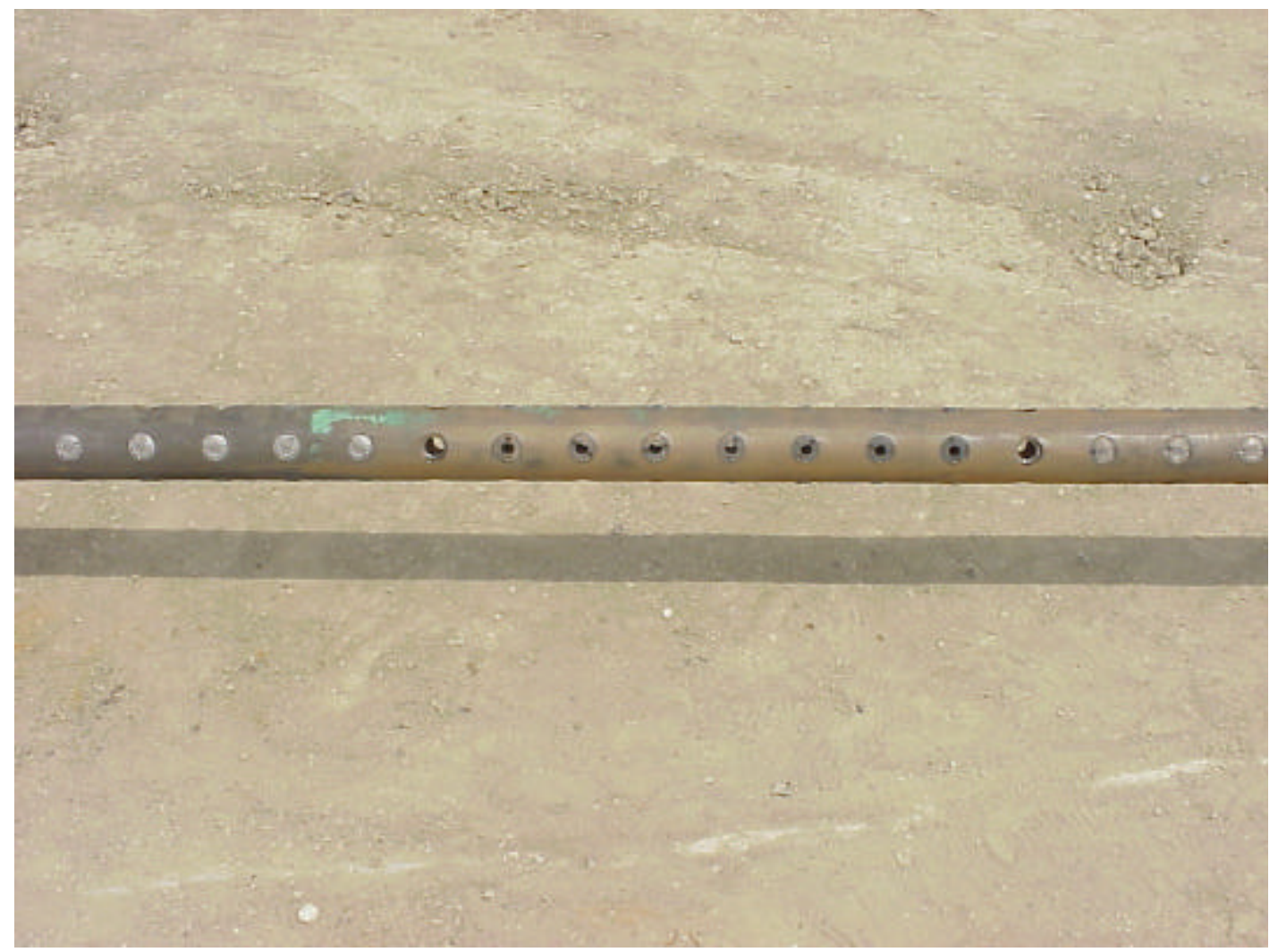

Picture 10. Well 61-A-3. Additional results from second gun. 


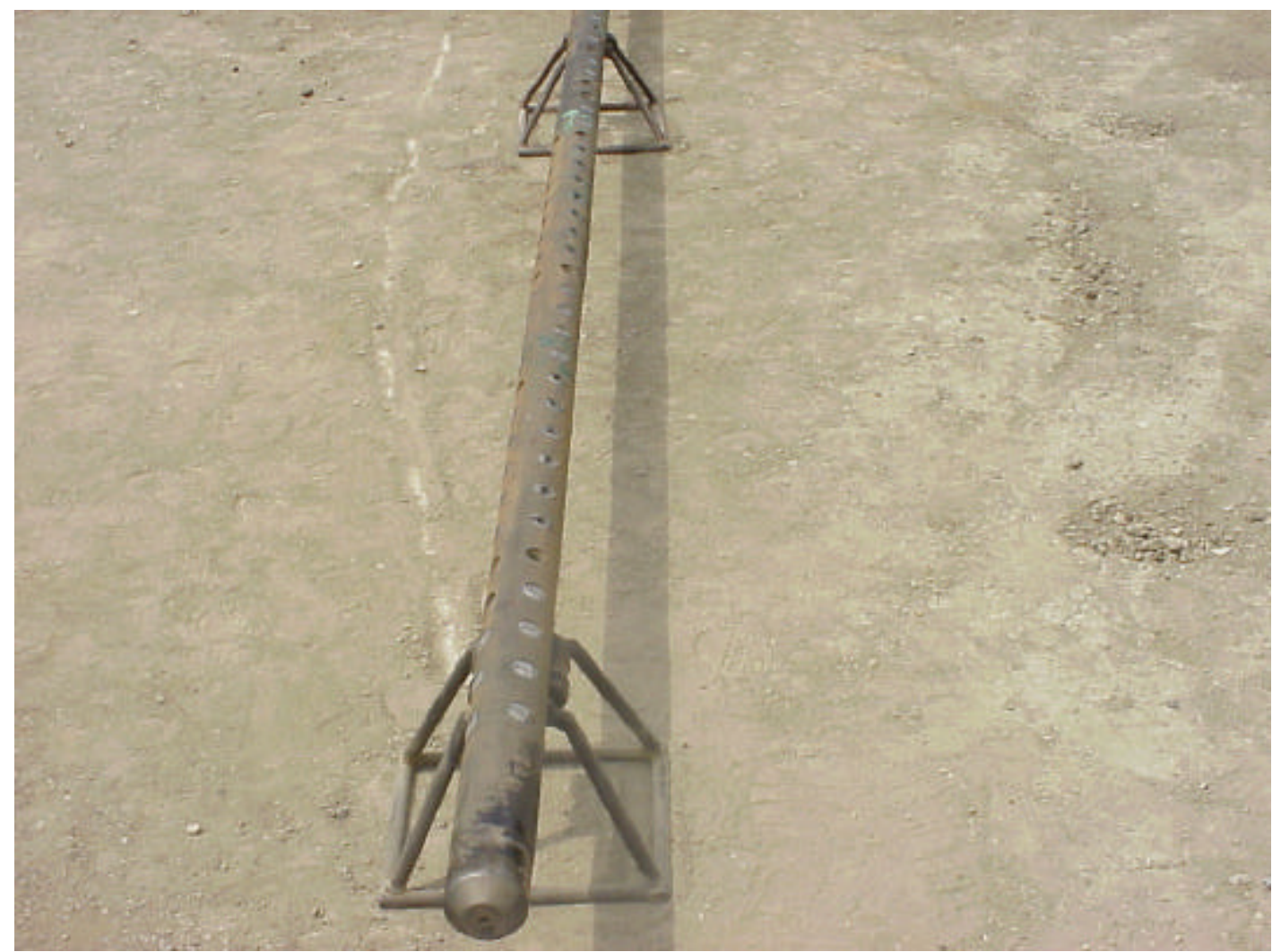

Picture 11. Well 61-A-3. Compare with Picture 7. Three rows of ports below bottom propellant section were either perforated or blown out. 